Arab Journal of Sciences and Research Publishing

Volume (6), Issue (4) : 30 Dec 2020

P: 120 - 134
AJSRP

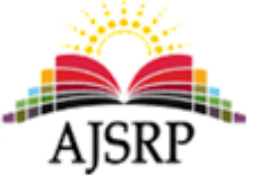

ISSN: 2518-5780
المجلة العربية للعلوم

ونشـر الأبحـاث

المجلد (6)، العدد (4) : 30 ديسمبر 2020 م

ص: 120 - 134

\title{
The extent to which private schools in Shafa Badran area, Amman, implement their educational and legal obligations to apply online education in light of Corona pandemic
}

\author{
Omar musa mahasneh \\ Shoubak College || Al-Balqa Applied University || Jordan
}

Othman Ibrahim bnitaha

Ministry of Justice || Jordan

\begin{abstract}
This study examines whether or not the outbreak of Corona Virus under the Jordanian Defense Law considers a legal impossibility "force majeure", and it determines the obligations of private schools in the online teaching with taking into account the satisfaction of students and their guardians. For this purpose, the descriptive survey approach has followed in this research by analyzing (34) questionnaires filled by the students' guardians.

From the educational side, the survey has reached that (97\%) of the guardians prefer the direct/traditional teaching while (3\%) prefer the online method; (65\%) believe that the online teaching applied by the private schools did not take care of the various needs of students; (70\%) think that non-direct communication (face to face) between the teachers and students was one of the main obstacles in the online teaching; and (90\%) see that WhatsApp was the only online way for teaching the courses.

From the legal side, the study has reached that the obligations of private schools changed from traditional teaching to online teaching because of the legal impossibility (majeure force) and the applied defense law. By other words, Unlike traditional teaching, the obligations of private schools have changed to online teaching and contacting as a new way since the outbreak of coronavirus.
\end{abstract}

Keywords: Online Teaching; Corona Virus; Carrying out the Obligations; Private Schools; The Educational Overview; the Legal Overview.

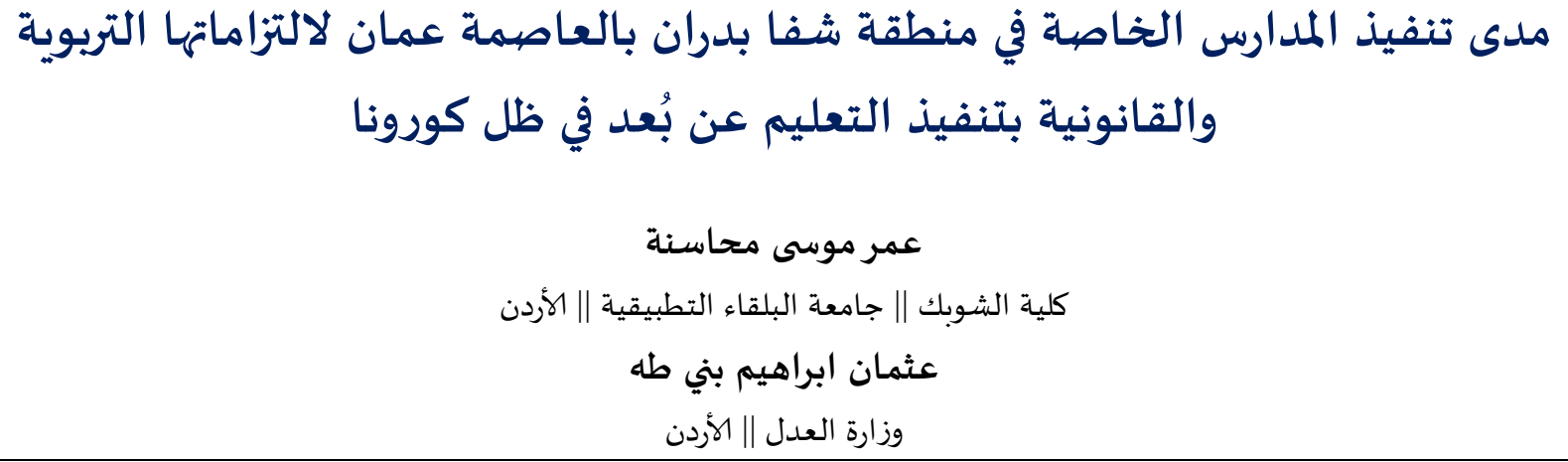

الملخص: هدفت الدراسـة إلى بيان مدى اعتبار ظروف انتشار وباء كورونا (COVID- 19)- في ظل إعلان العمل بقانون الدفاع الأردني- من

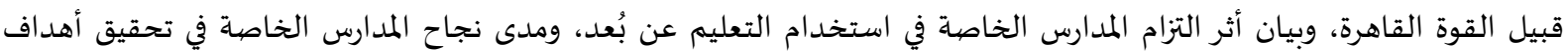


التعليم، والوفاء بالتزاماتها تجاه الطلبة وأولياء أمورهم. واستخدمت الدراسة المنهج الوصفي المستي من خلال أداة الاستبانة

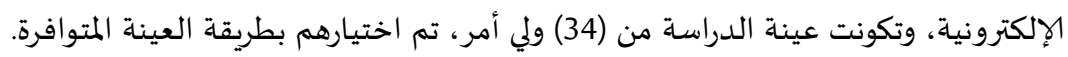

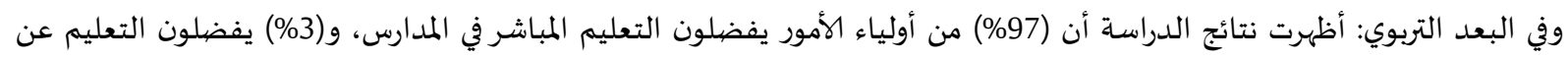

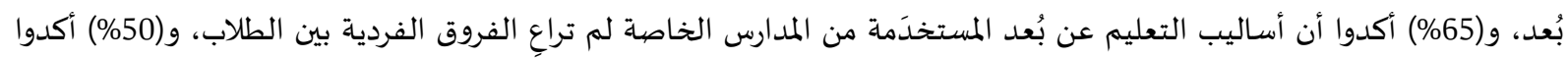

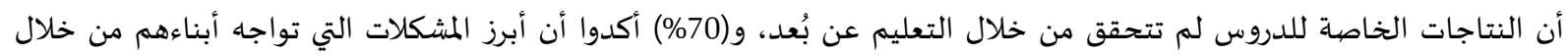

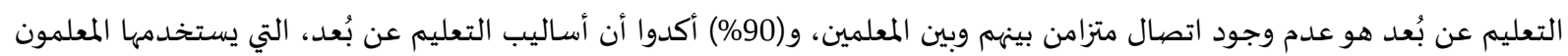

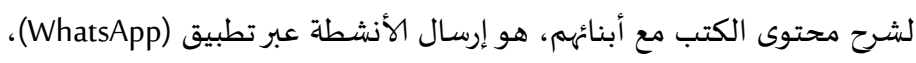

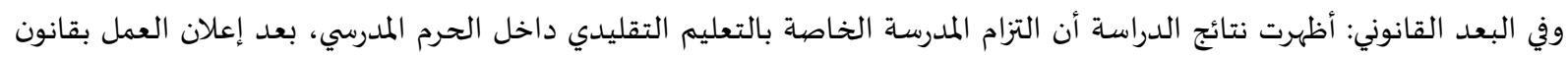

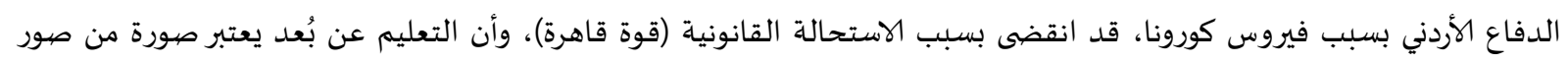

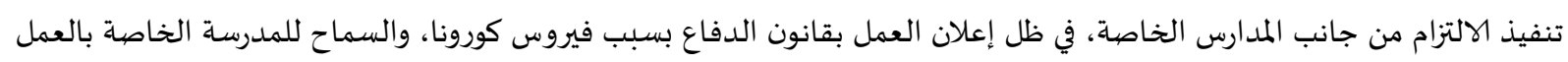

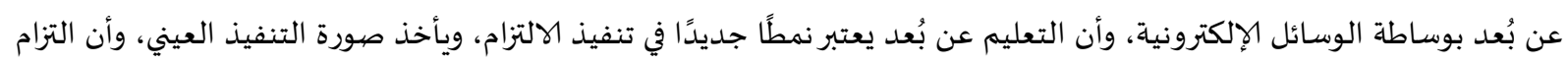

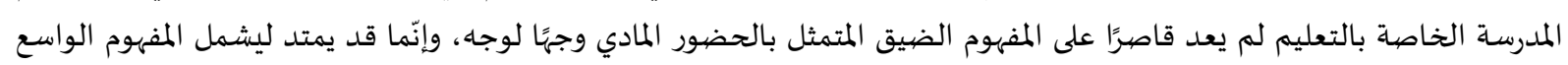

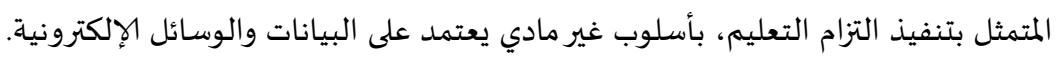

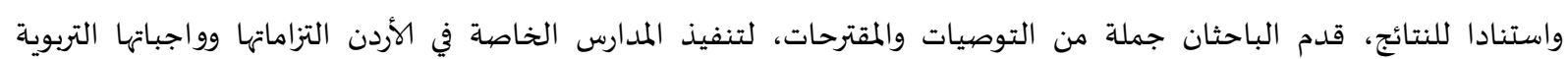

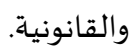

الكلمات المفتاحية: التعليم عن بُعد، جائحة كورونا، صور تنفيذ الالتزام، المدارس الخاصة، البعد التربوي، البعد القانوني.

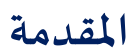

بدأ مفهوم التعليم عن بُعد عام 1856م، عندما قام شارل توسان بإنشاء أول مدرسة للتعليم عن بُعد في

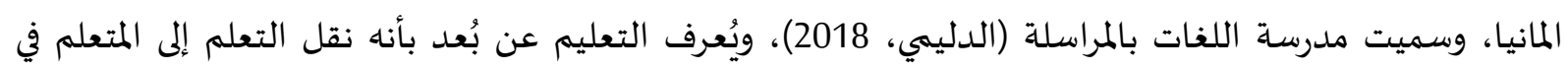

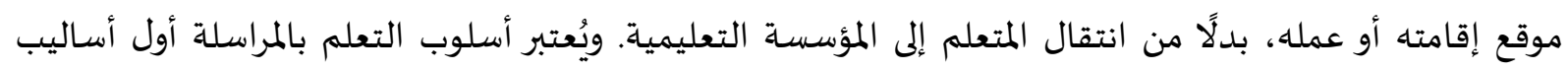

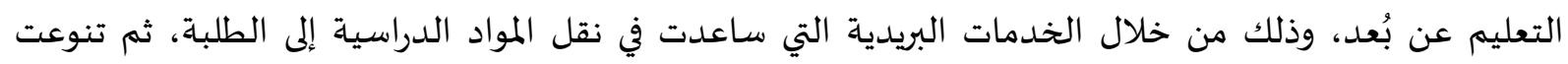
أساليب التعليم عن بُعد من خلال البث الاذاعي والتلفزيون وأجهزة التسجيل.

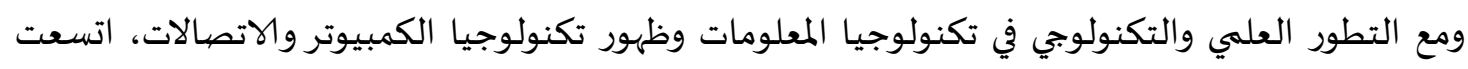

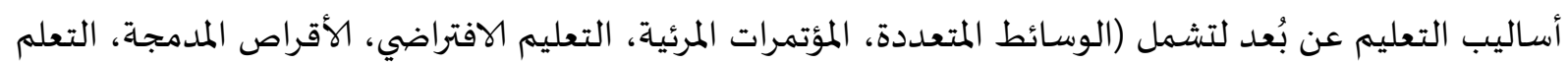

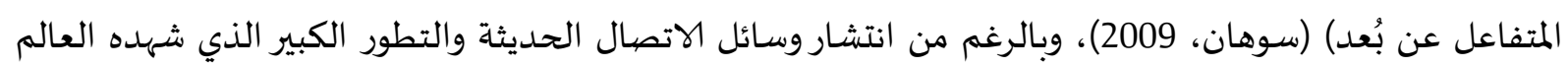

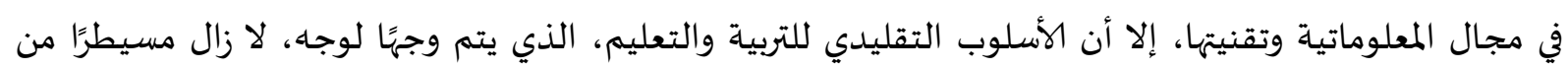

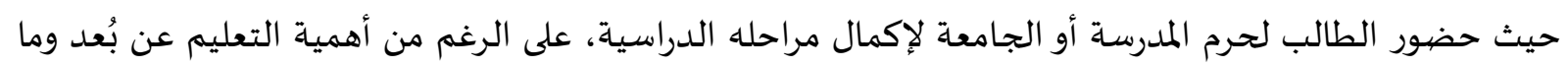

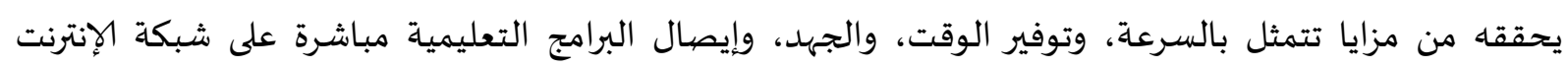

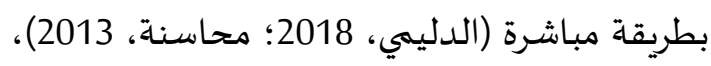
إن أساليب التعليم عن بُعد متعددة ومتنوعة، ومن أفضلها: الأساليب التي تشجع على استخدام المتعلم

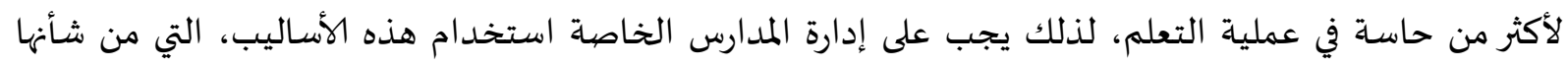

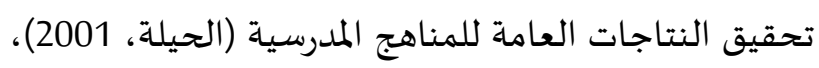
وبعد إعلان العمل بقانون الدفاع الأردني بتاريخ 2020/3/17، بسبب جائحة كورونا في المملكة الأردنية

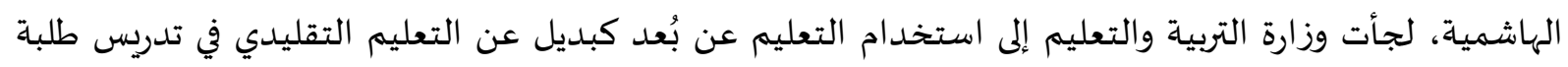

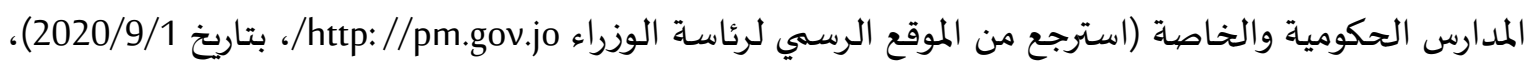


ومن هنا جاءت هذه الدراسة للكشف عن التعليم عن بُعد في ظل كورونا، كوسيلة لتنفيذ التزام المدارس

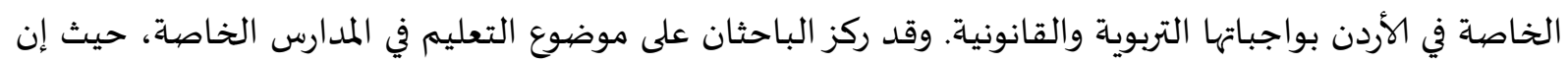

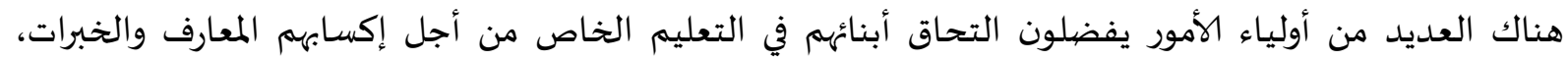

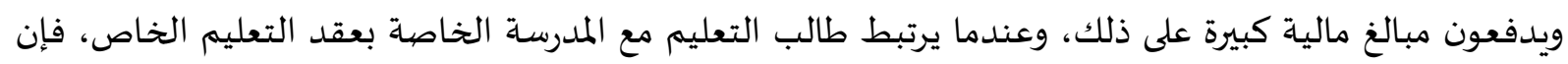

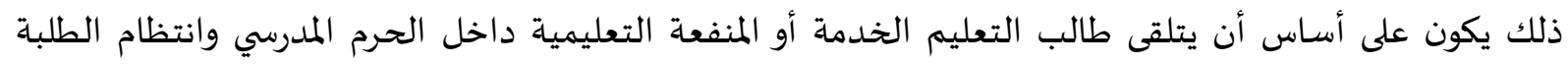

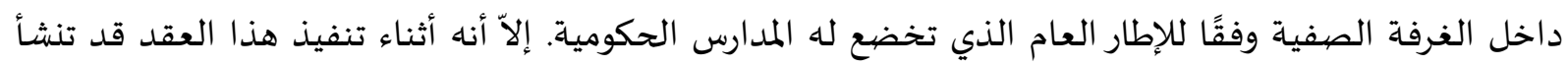

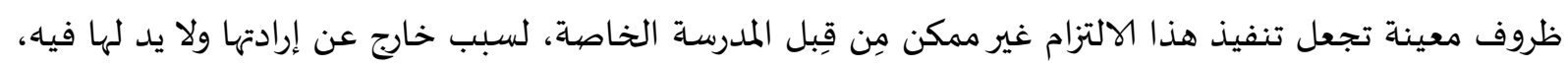

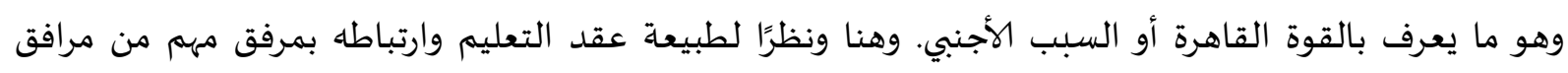

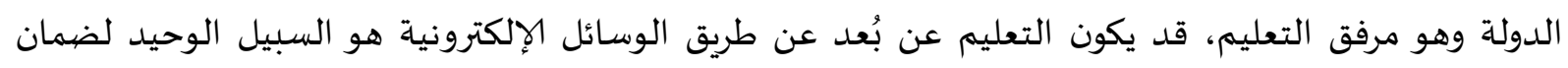
ديمومة تعليم الطلبة. وقد بينت نتائج الاستطلاع الذي نُفذ من خلال مكتب منظمة الأمم المتحدة للتربية والعلم والثقافة (يونسكو) في بيروت خلال شهر أيار/2020 أن أكثر من 80 \% من أولياء الامور المستطلَعة آراؤهم اعتبروا أن التعليم

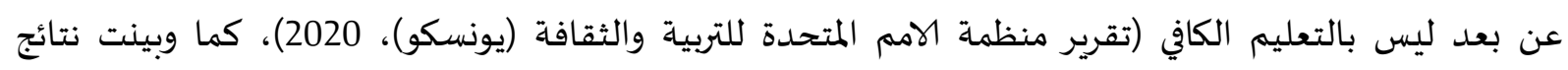

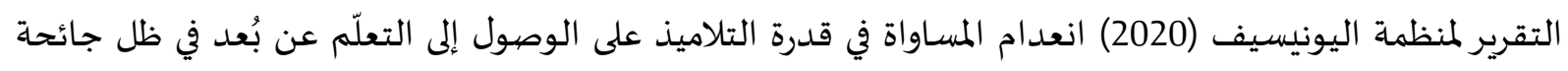
كوفيد- 19.

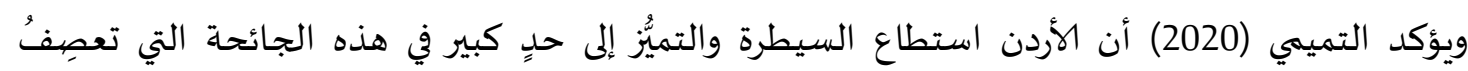

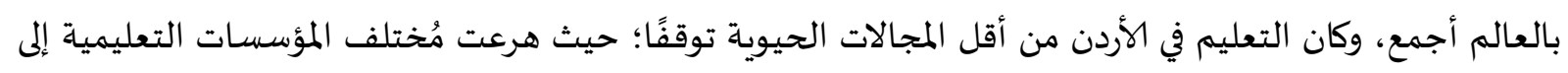

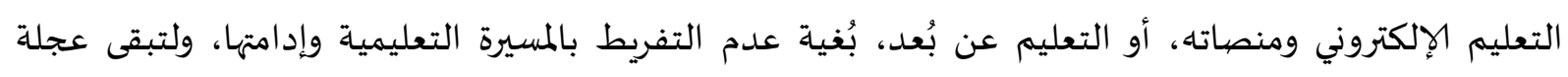

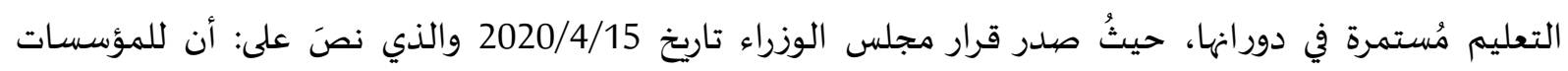

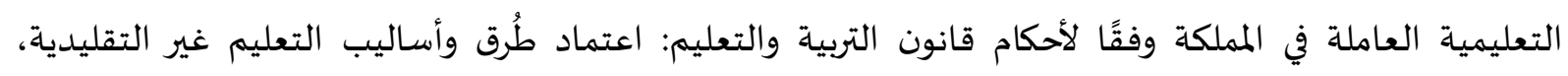

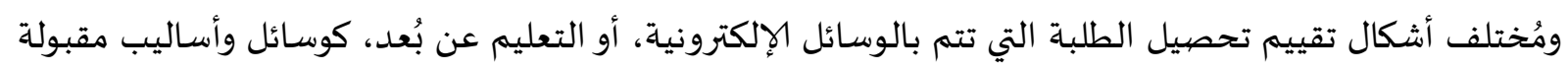

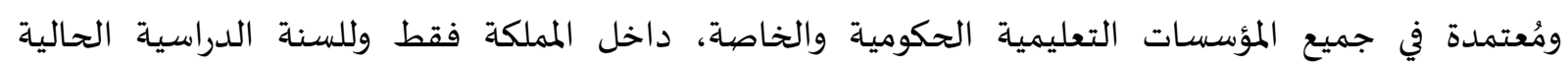

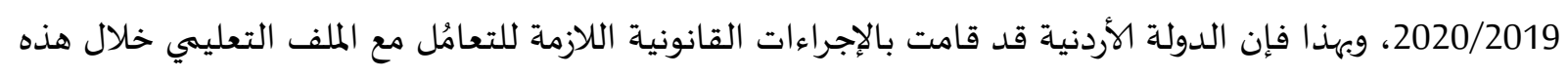
الجائحة، من قبل كافة الأطراف المعنية في العملية التعليمية.

وعلى صعيد التعليم العالي، فقد باشرت الجامعات في تعزيز عملية إدماج التكنولوجيا بالمنظومة التعليمية،

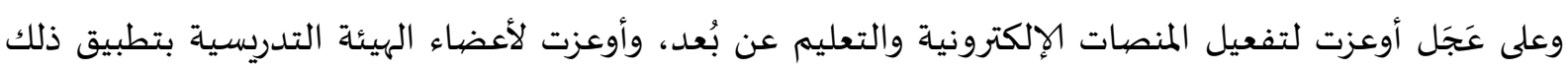

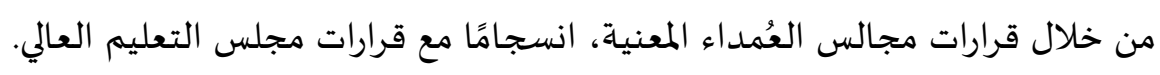

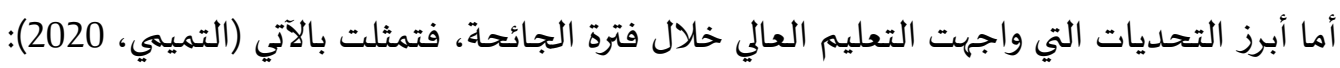

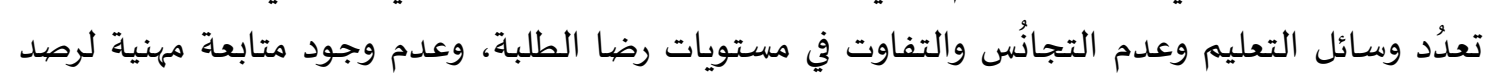

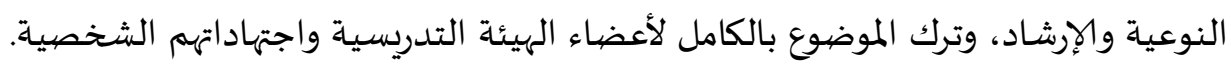

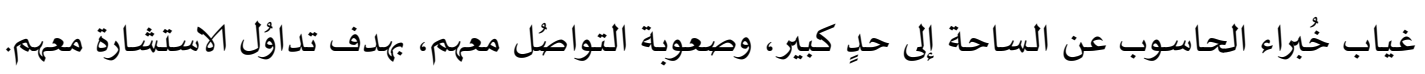

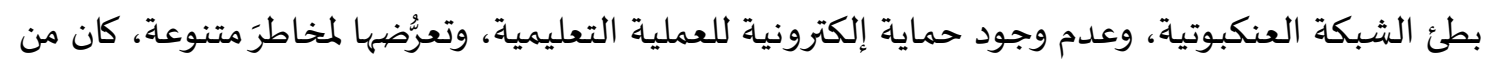

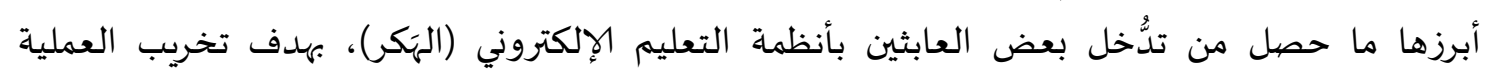

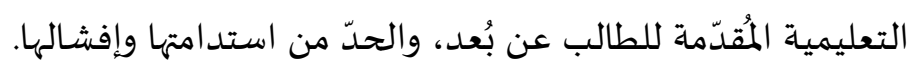


- عياب ثقافة التعليم الإلكتروني عن أعضاء الهيئة التدريسية، وضعف البُنية التحتية للجامعات في هذا

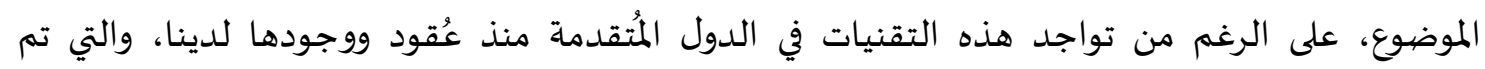
التعامُل معها بشكل ديكوري فقط.

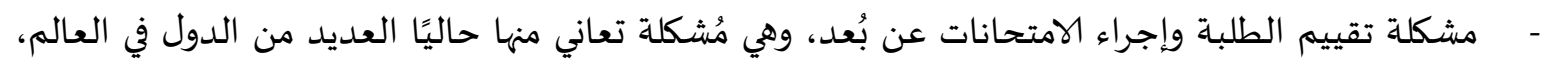

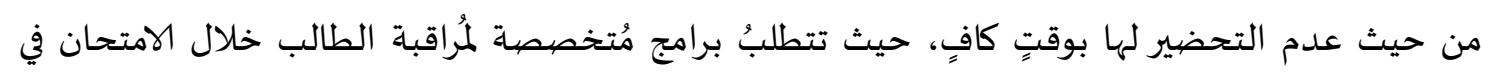

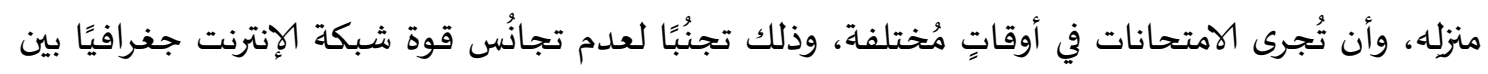

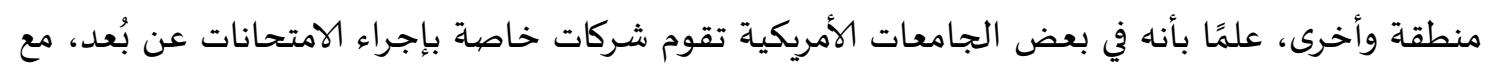
توفير ما يضمن عدم وجود أي خلل في الامتحان.

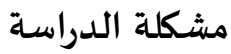

اتخخَذت حكومة المملكة الأردنية الهاشمية إجراءات وقائية ضد انتشار جائحة كورونا، ومن ضهمن هذه

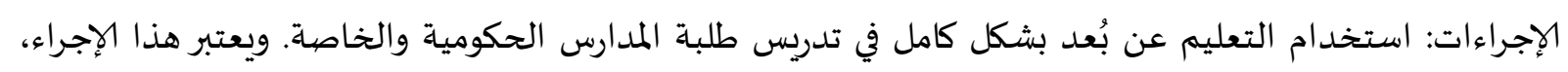

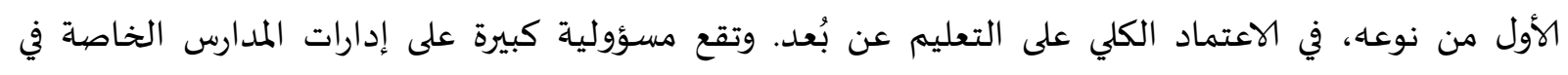

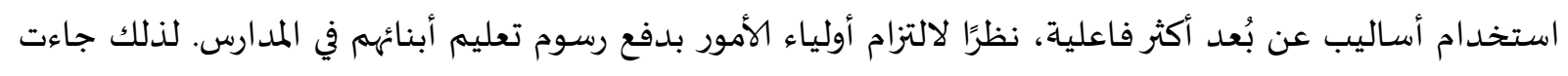

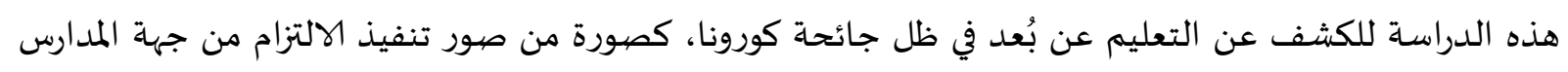

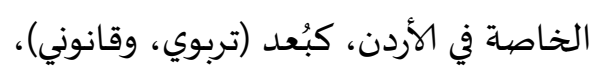

أسئلة الدراسـة:

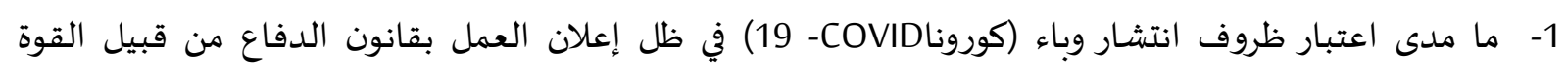

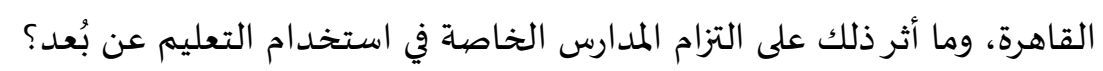

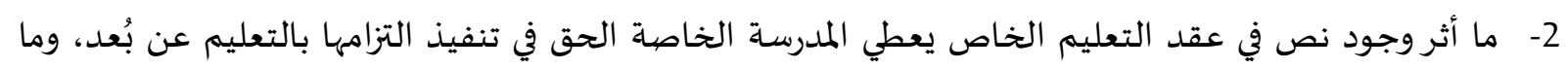

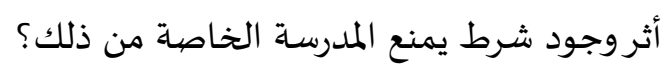

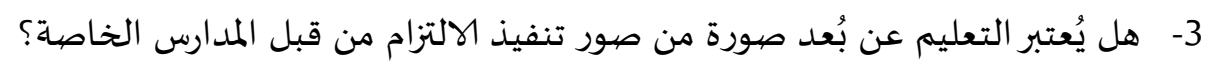

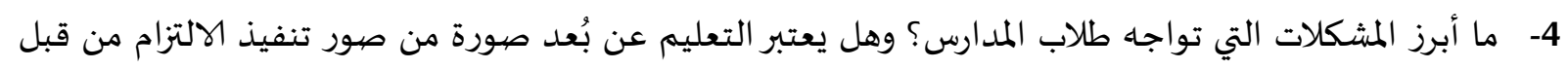

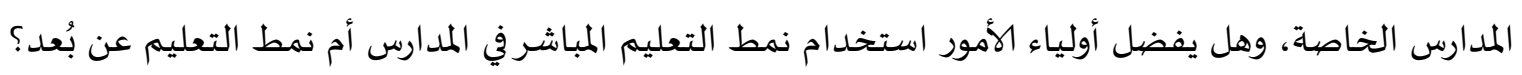

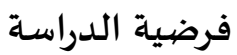

تثير الدراسة مجموعة من الفرضيات، وتتمثل في الفرضيات الآتية:

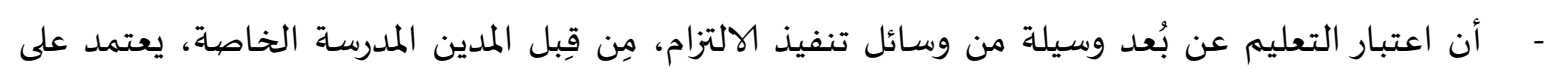

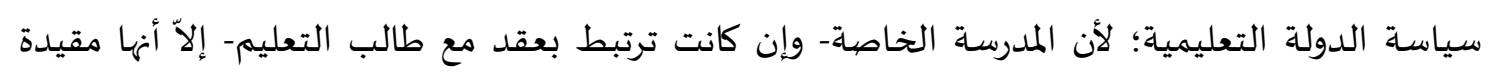
بقانون وزارة التربية والتعليم.

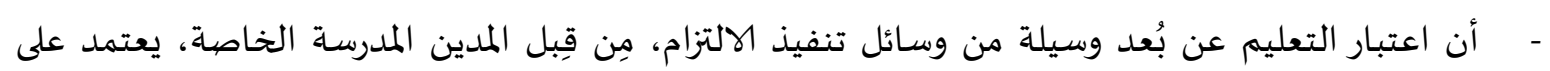
التنظيم التشريعي لهذه الصورة من صهور التنفيذ.

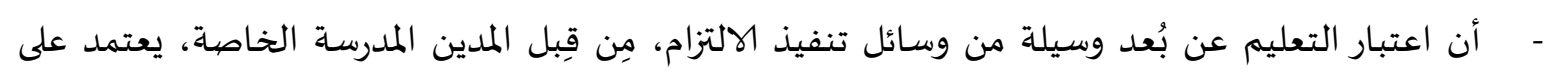

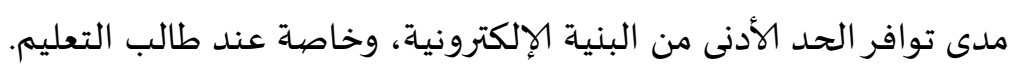


هدفت الدراسـة إلى:

1. بيان مدى اعتبار ظروف انتشار وباء كورونا (COVID- 19)، في ظل إعلان العمل بقانون الدفاع، من قبيل

القوة القاهرة.

2. التعرف على مدى تنفيذ المدارس الخاصة للتعليم عن بعد؛ ومدى وفائها بالتزاماتها التربوية والقانونية. 3. تحديد أبرز السلبيات والمشكلات التي واجهت طلاب المدارس الخاصية، خلال التعليم عن بُعد، من وجهة نظر

أولياء الأمور.

أهمية الدراسـة

تظهر أهمية الدراسـة، من أهمية موضيوعها ذاته، وحداثة التجربة،، وبذلك يأمل الباحثان أن تفيد نتائج الدراسـة على النحو الآتي:

قد تفيد في كشف بعض جوانب الغموض القانونية حول التعليم عن بُعد- إذا ما اعتبر وسيلة من وسائل تنفيذ الالتزام من قبل المدارس الخاصية- فإنّه يحافظ على استمرارية العلاقة العقدية بين الأطراف وتجنب مخاطر الفسخ أو وقف التنفيذ المتمثلة بانقطاع الطلبة عن التعليم، لذا يعتبر التعليم عن بُعد أهم البدائل لتنفيذ الالتزام العيني من قبل المدين (المدرسـة الخاصهة)، قد تفيد في تنبيه مدراء مدارس التعليم الخاص في وضع معالجات وحلولًا للسلبيات التي رافقت أداء مدارسهم خلال العام الدراسي المنصرم، وبما يضمن عدم تكراراها مرة أخرى. من المتوقع أن تنعكس نتائج الدراسة في زيادة رضا الطلبة وأولياء أمورهم عن خدمة التعليم والناتج عن تحسين جودة أداء المعلمين في مدارس التعليم الخاص.

- - دراسـة هذا الموضوع يعتبر هامًا للباحثين والمهتمين؛ لإجراء دراسات مماثلة حول موضوع الدراسـة. - تُعتبر دراسـة هذا الموضيوع إضيافة نوعية للمكتبة التربوية، وتُعتبر من الدراسات الحديثة حول موضيوع الالتزام القانوني للمدارس الخاصية.

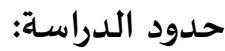
الحدود الموضيوعية: مدى تنفيذ المدارس الخاصة لالتزاماتها التربوية والقانونية بتنفيذ التعليم عن بُعد في ظل كورونا. الحـدود البشرية: أجري البحث على أولياء الأمور الملتحقين أبناؤهم في المدارس الخاصة الحدود المكانية: المدارس الخاصة في منطقة شفا بدران- حي الكوم في محافظة العاصهمة. الحدود الزمانية: أجري البحث خلال الفصل الثاني من العام الدراسي 2020/2019.

التعريفات الإجرائية

- التعليم عن بُعد: يقصيد بالتعليم عن بُعد وجود مسافة ومواقع مختلفة تفصل بين المعلم والطالب، وبموجباه يقوم المعلم بإيصال البرامج التعليمية عن طريق شبكة الإنترنت بالصوت أو الصيورة أو الطباعة أو الفيديو، بحيث يكون هناك تفاعل وتواصل بين المعلم والطالب، يتلقى المعلم ملاحظات الطلاب عبر قنوات الاتصال، بما يحقق التفاعل الإيجابي، من حيث الفهم التام للطالب وإحاطة المعلم باحتياجات الطالب ونقاط ضعفه وتقييماه (سوهام، بادي، رسالة ماجستير: ص55). 
جائحة كورونا: هي جائحةٌّ عالمييٌّ جارية لمرض فيروس كورونا (19 (19).

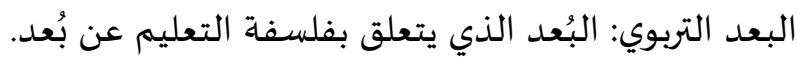

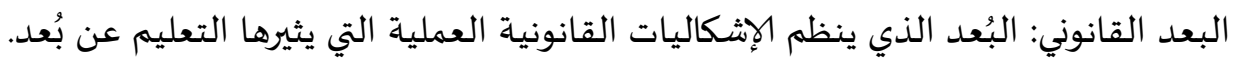

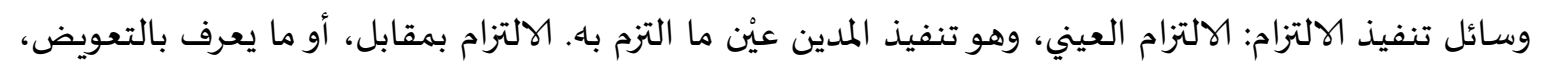
ويكون في حالة استحالة التنفيذ العيني.

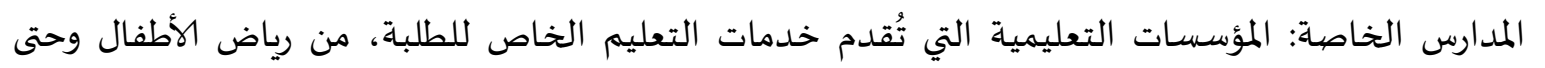
الصف الثاني الثانوي. عقد التعليم الخاص: قُصدد بعقد التعليم الخاص بأنه رابطة عقدية بين مؤسسة تعليمية وبين طالب التعليم،

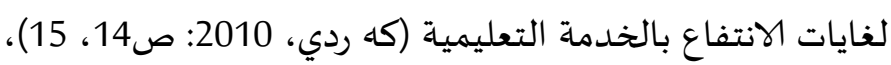

1- الإطار القانوني لعقد التعليم الخاص يَفرض عقد التعليم الخاص على المدرسة الخاصة التزامًا يتمثل بتقديم الخدمة أو المنفعة في مجال التعليم

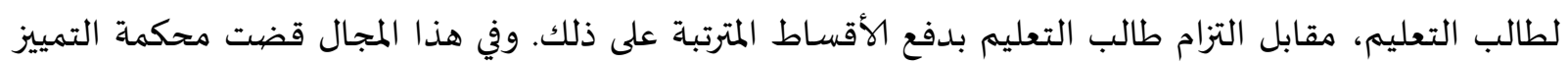

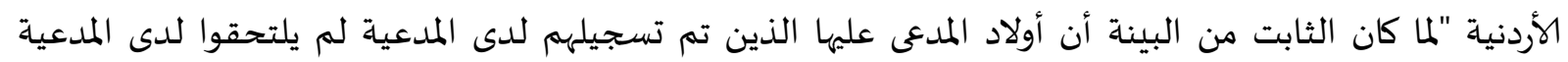

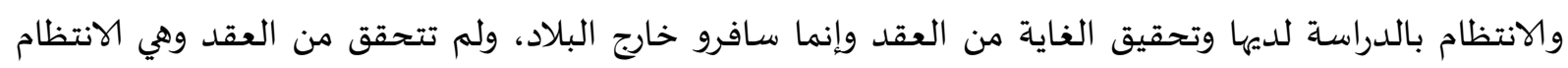

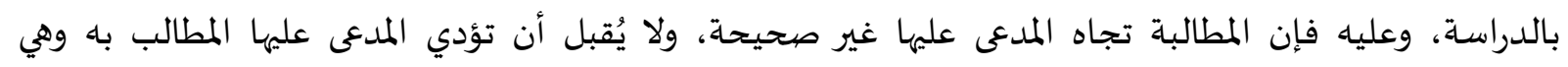

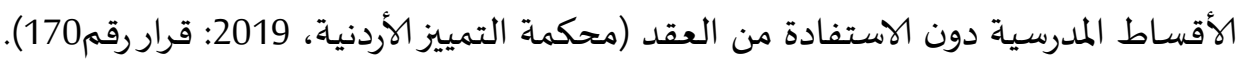

أولًا: خصيائص عقد التعليم الخاص

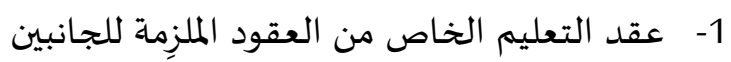

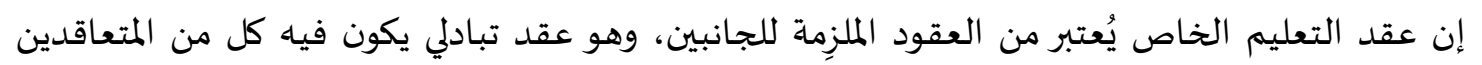
دائًا ومدينًا في الوقت نفسـه، فالجهة التعليمية (المدرسة الخاصةة) عليها التزام عقدي يتمثل بتعليم طالب التعليم

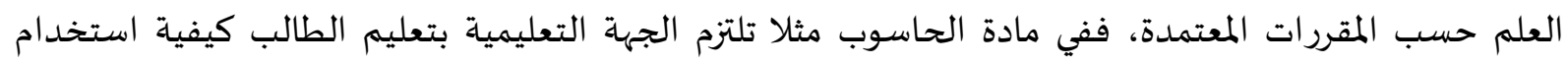

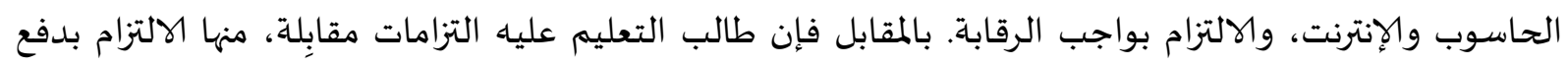

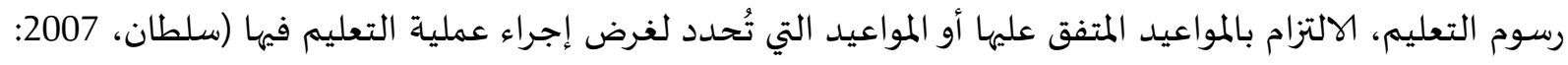

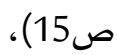
2- 2 عقد التعليم الخاص من العقود الزمنية المستمرة إن عقد التعليم الخاص من العقود الزمنية المستمرة؛ لأن عملية التعليم بحد ذاتها تستغرق وقتًا، وتتم

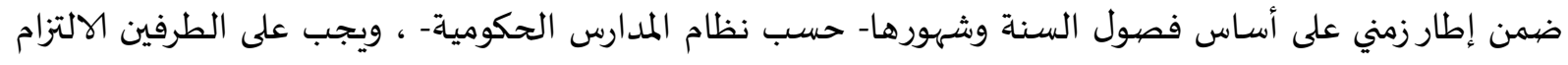

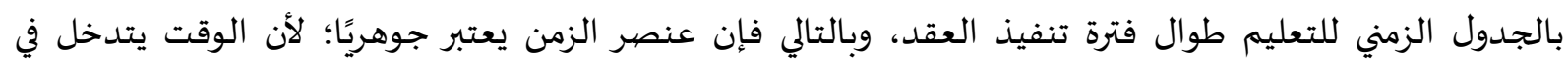

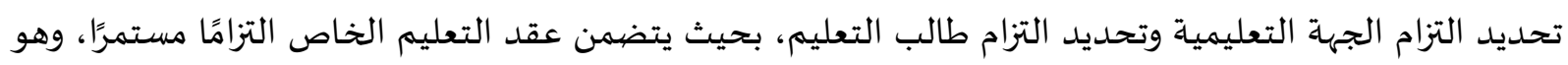

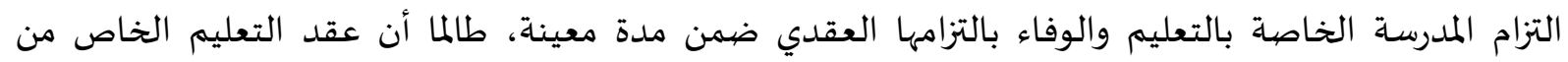

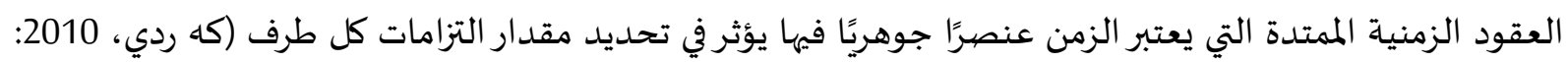


وتظهر أهمية هذا التقسيم في مجال نظرية الظروف الطارئة، حيث إن هذه النظرية مرتبطة بالعقود الزمنية دون العقود الفورية؛ لأن التزامات المدرسة الخاصة في عقد التعليم الخاص تستوفى على التراخي (المادة 205

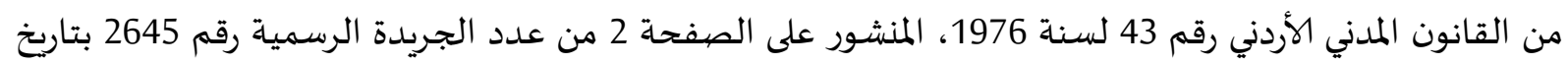

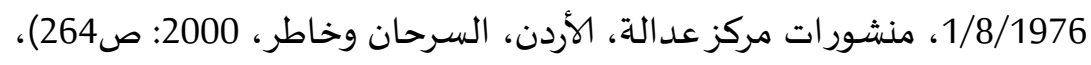

ثانيًا: مدى اعتبار التعليم عن بُعد وسيلة لتنفيذ الالتزام.

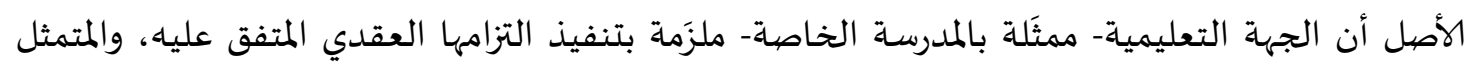

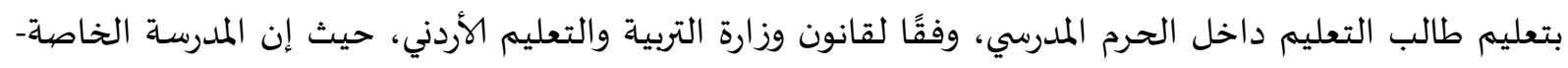

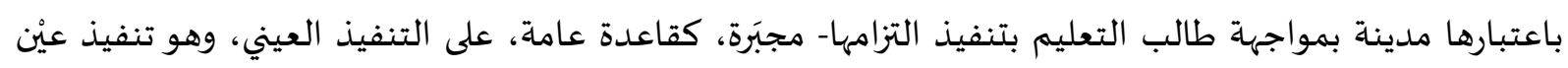

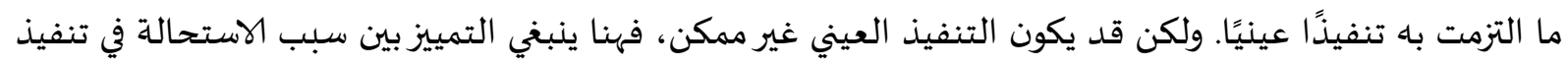

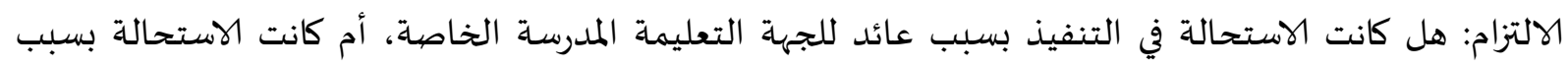
خارج عن إرادتها كمدين.

1- - استحالة تنفيذ المدرسة الخاصية لالتزامها.

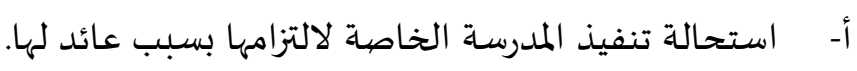

إذا كانت المدرسة الخاصة قد استحال عليها تنفيذ التزامها العيني المتمثل- بتعليم طالب التعليم داخل

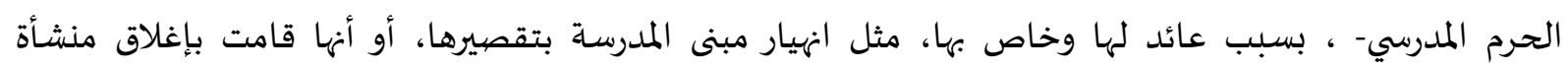

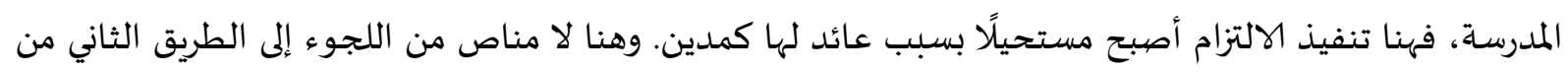

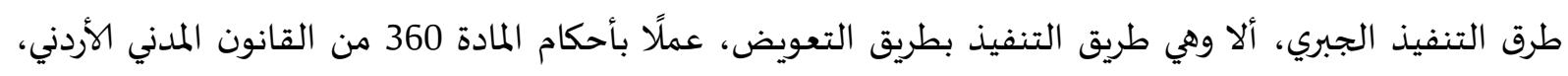

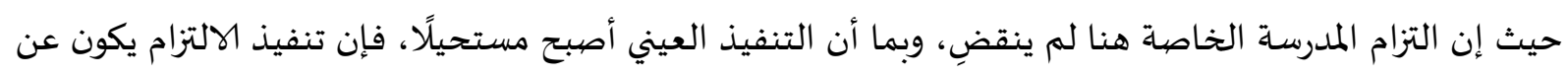

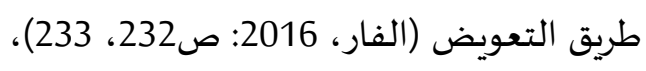

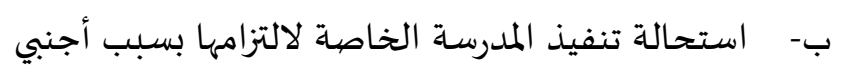

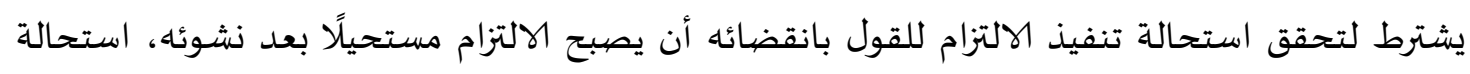

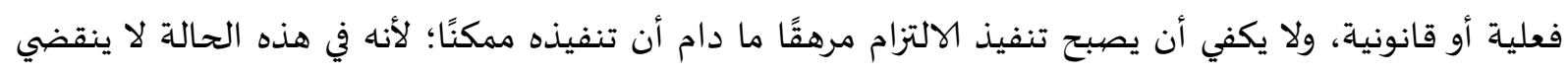

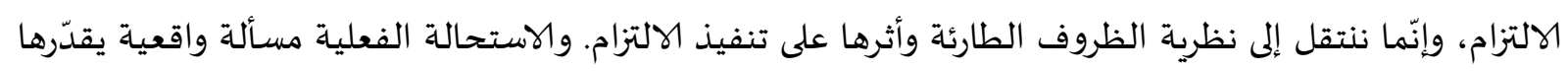

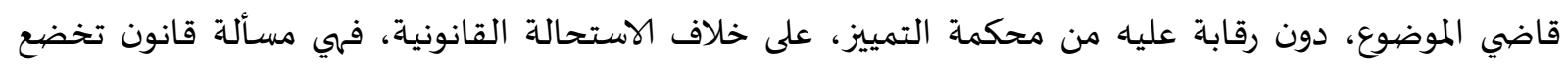

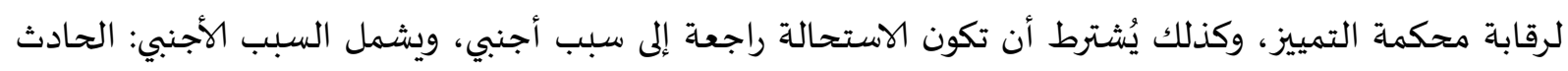

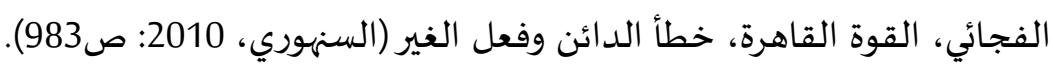
وعليه، إذا كانت المدرسة الخاصة قد استحال علهيا تنفيذ التزامها العيني- المتمثل بتعليم طالب التعليم

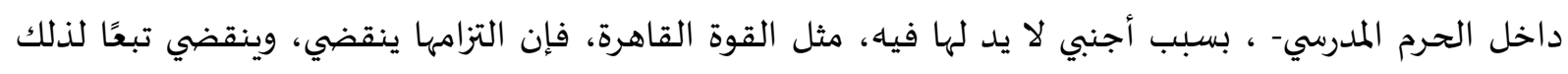

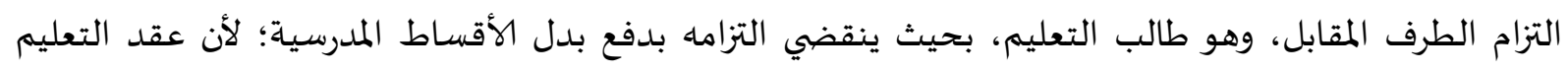

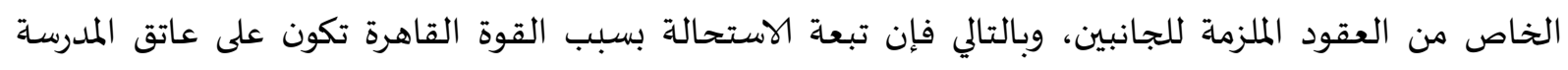

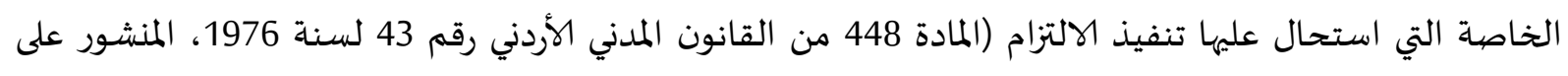

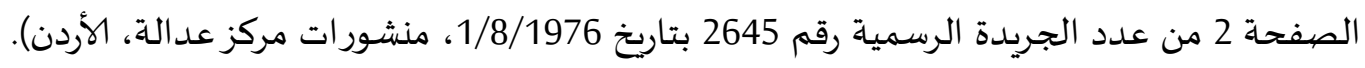

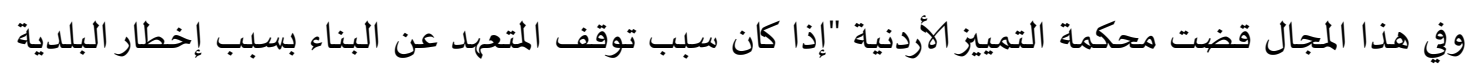

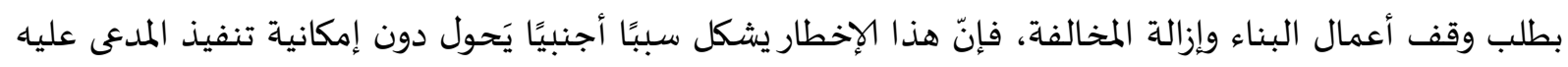


لتعهده بالاستمرار في إكمال بناء المدعي، وتكون استحالة التنفيذ هنا هي استحالة قانونية" (محكمة التمييز الأردنية،

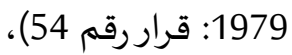
"نجد أن المستفاد من المادة (247) من القانون المدني أن الالتزام ينقضي إذا استحال تنفيذه وكانت هذه

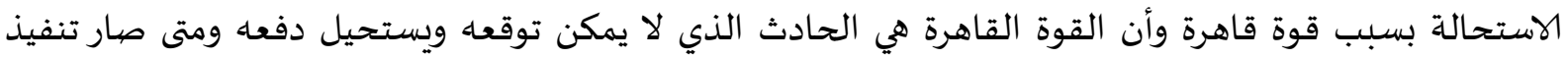

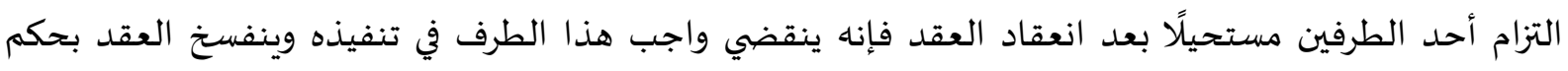

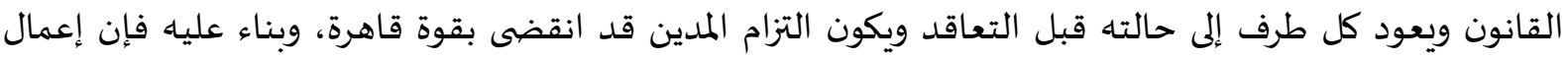

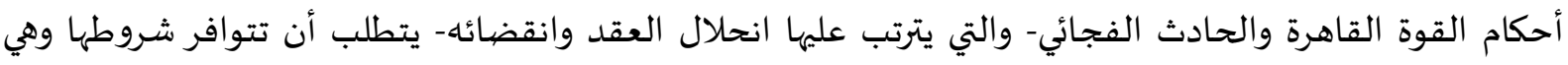

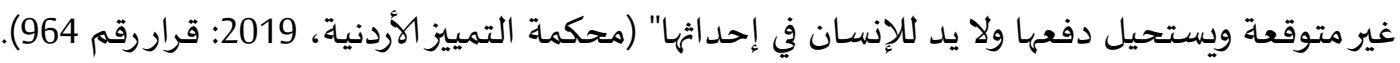

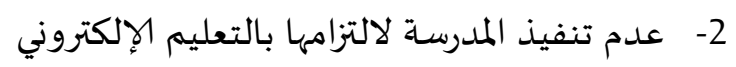

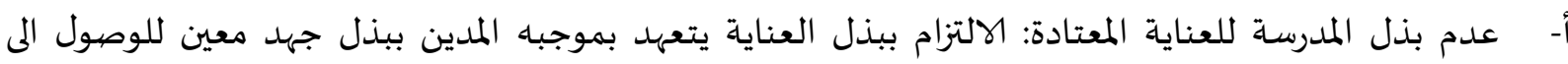

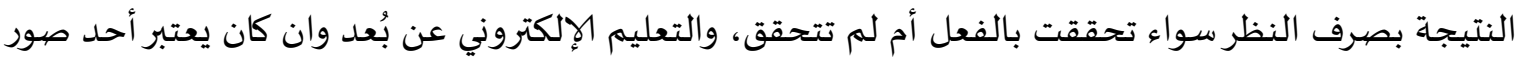

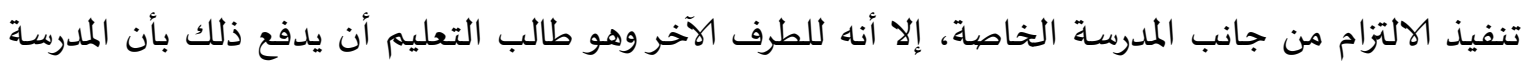

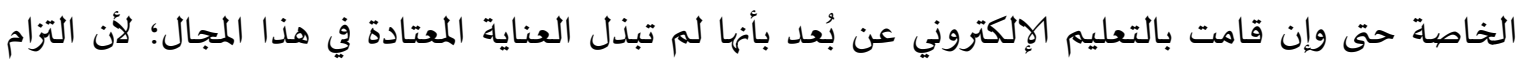

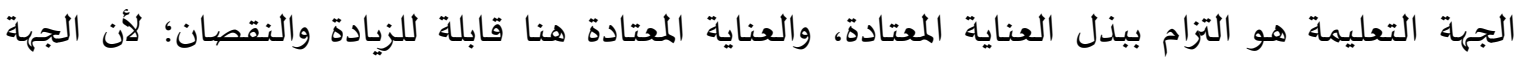

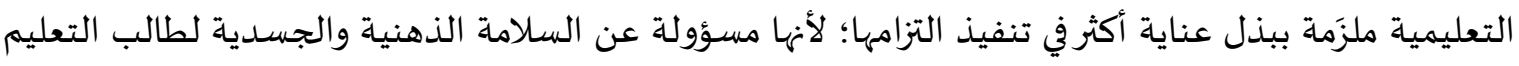

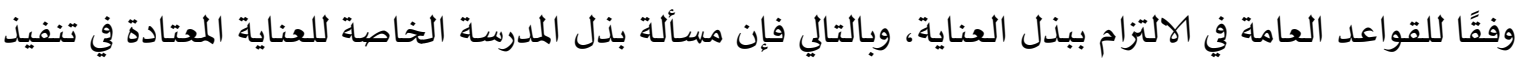

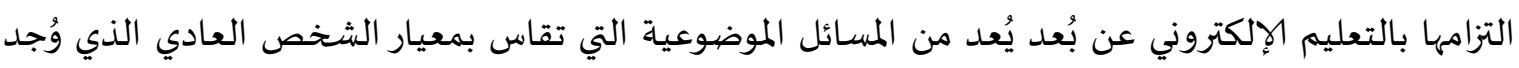

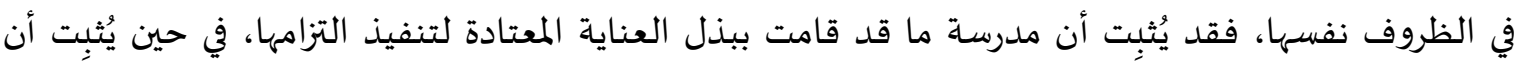

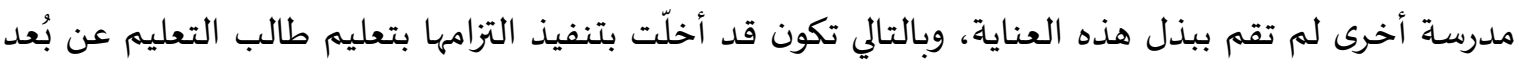

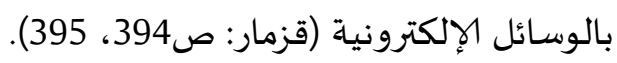

ومن الظروف المحيطة التي تسـاعد في بيان مدى بذل المداندة المدرسة الخاصة للعناية المعتادة: مدى التفاعل بين

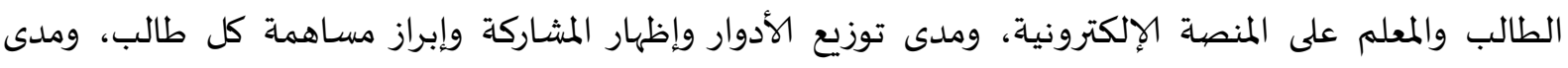

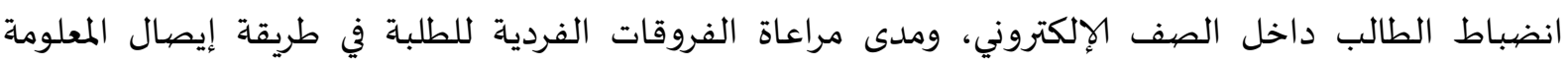

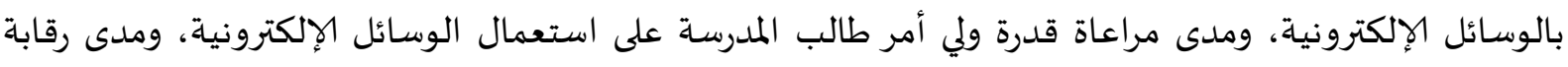

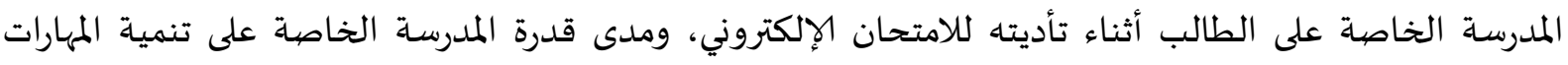

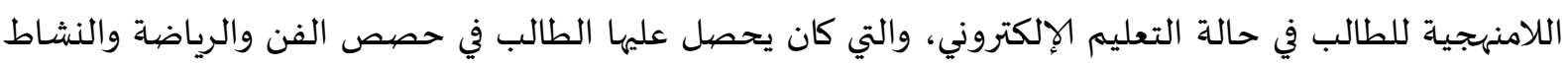

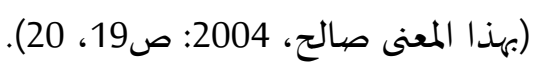

ب- الإرهاق المرافق للتعليم عن بُعد: يتمسك طالب التعليم بأن تنفيذ التزامه بدفع الأقساط المدرسية قد أصبح

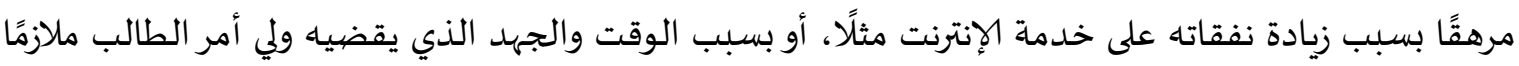

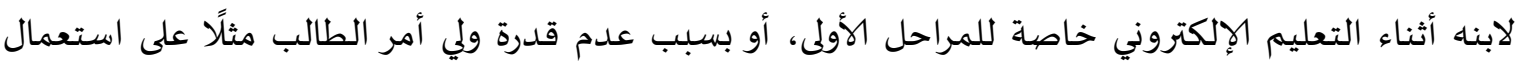

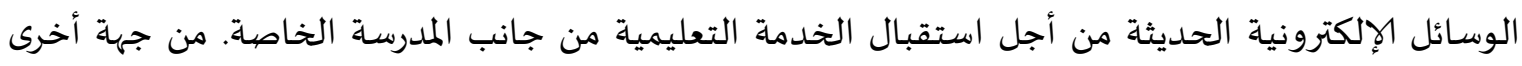

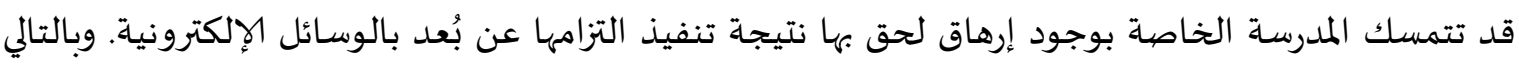

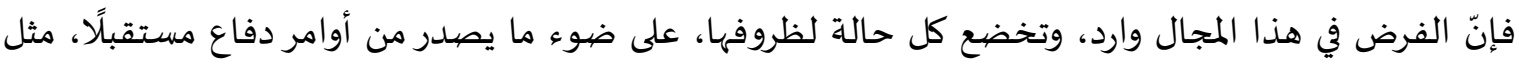

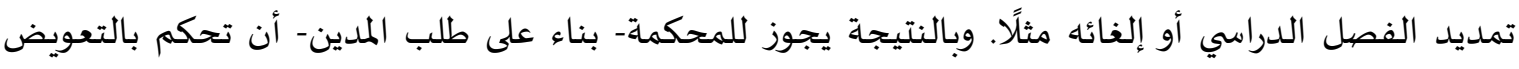

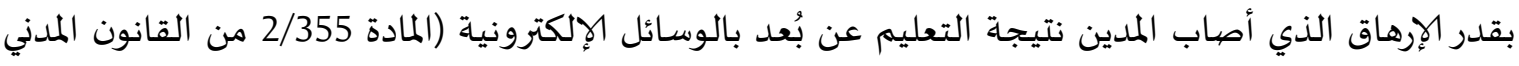


الأردني رقم 43 لسنة 1976، المنشور على الصفحة 2 من عدد الجريدة الرسمية رقم 2645 بتاريخ 1/8/1976،

$$
\text { منشور ات مركز عدالة، الأردن). }
$$

\section{2- الإطار النظري والدراسات السـابقة}

بعد مراجعة الأدب النظري والدراسات السابقة، وفي حدود إطلاع الباحثيْن، فقد عُثر على دراسات لها علاقة في موضوع الدراسة، وأهمها:

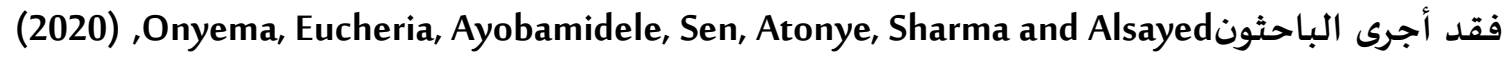
دراسة بعنوان تأثير جائحة فيروس كورونا على التعليم، تم جمع البيانات من خلال استبيانات منظمة تم

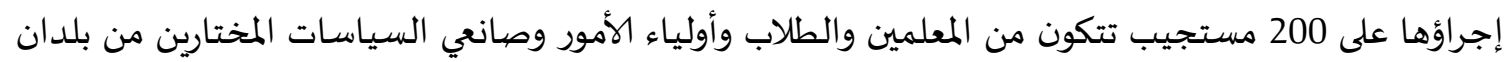

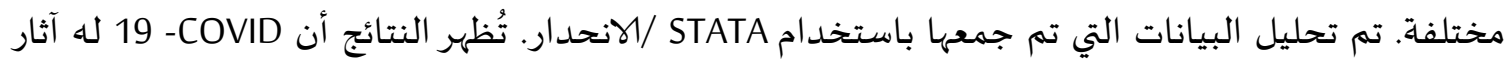

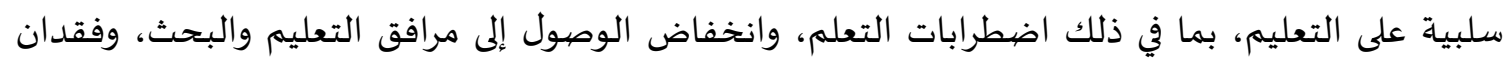

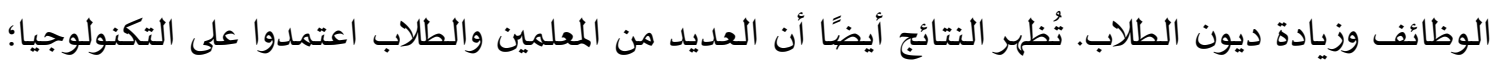

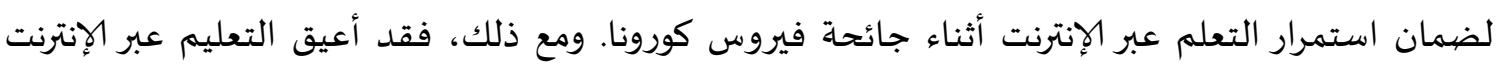

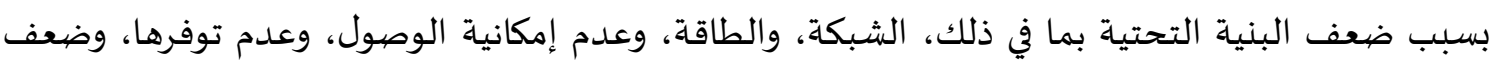

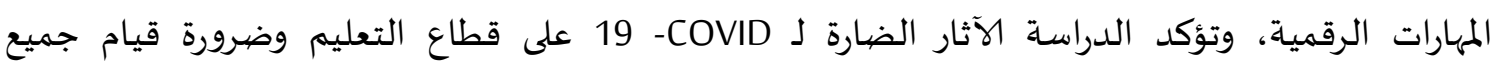

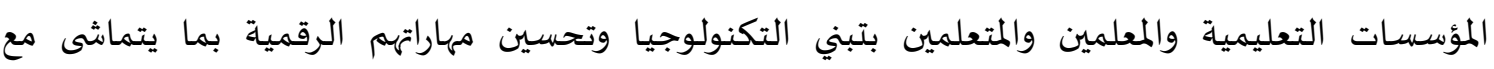

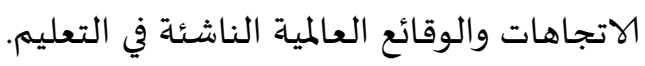
وأجرى Basilia and kvavadze (2020) دراسة بعنوان الانتقال إلى التعليم عبر الإنترنت في المدارس أثناء جائحة فيروس كورونا المستجد (COVID- 19) في جورجيا. قدم المؤلفان دراسة حالة، حيث تم تنفيذ منصية

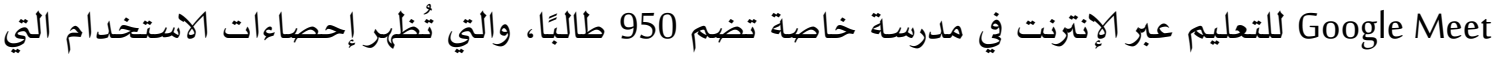

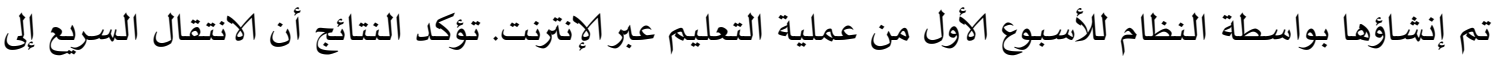

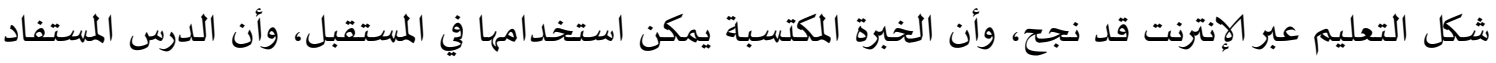

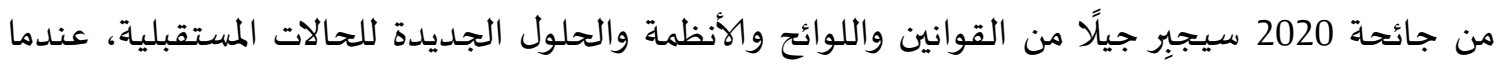

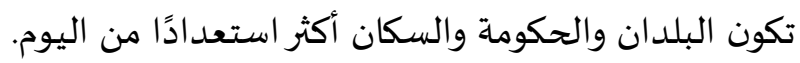
ونفذ Basilia, Dgebuadze, Kantaria, and Chokhonelidze (2020) دراسة بعنوان استون استبدال نموذج التعلم الكلاسيكي في الجامعات كاستجابة فورية لـ عدوى فيروس COVID- 19 في جورجيا. استخدم الباحثون

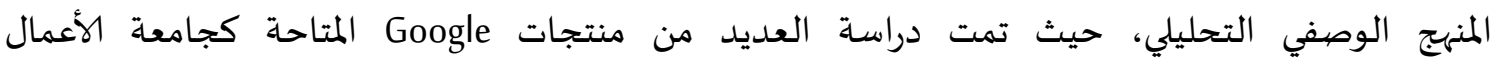
والتكنولوجيا، وجورجيا بالفعل المشترك في G Suite for Education مجانًا. تم اعتبار استخدام 8 منتجات بالشكل الجديد من التعليم: Gmail- لتبادل المعلومات، Classroom- لخلق بيئة تعليمية مع مشاركة الموادي؛

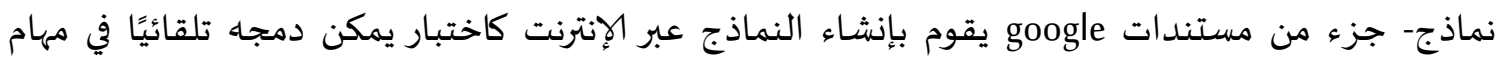
الفصل الدراسي؛ التقويم- أداة جدولة المحاضرات عبر الإنترنت، Drive- تخزين للمحاضرات المسبجلة، إلماتهات

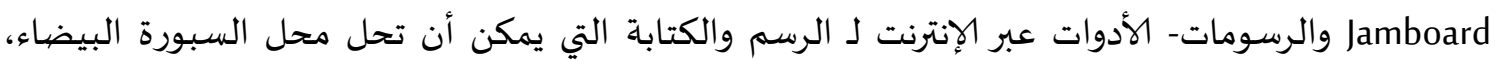

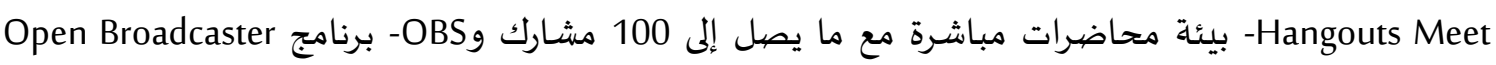

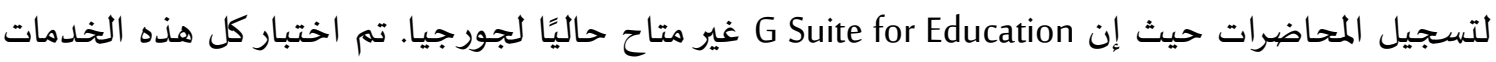
بنجاح وهي جاهزة للإنتاج. 
وقام Sintema (2020) بدراسة بعنوان تأثير COVID 19 على أداء طلاب الصف الثاني عشر: الآثار المترتبة

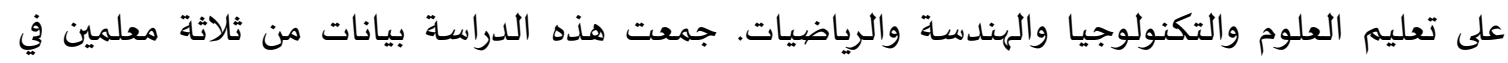

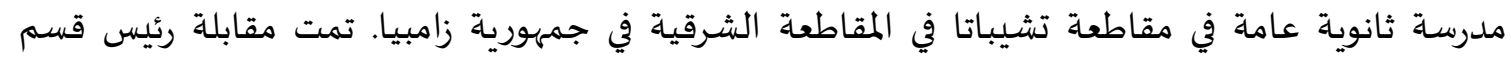

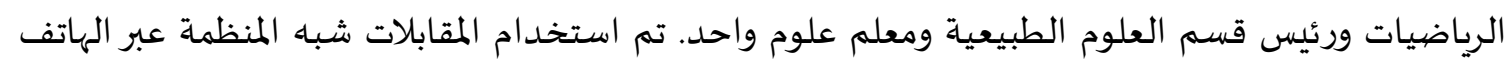

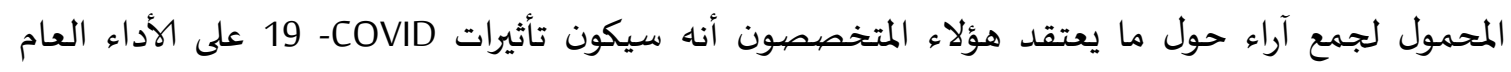

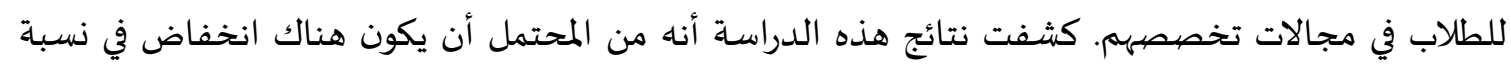

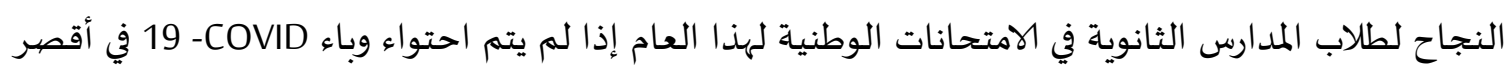

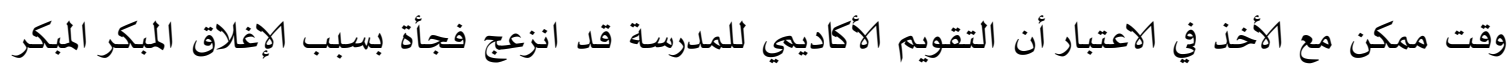
لو لجميع المدارس في البلاد. وأجرى Mustafa (2020) دراسة بعنوان تأثير جائحة فيروس كورونا 2019- 20 على التعليم، استخدم

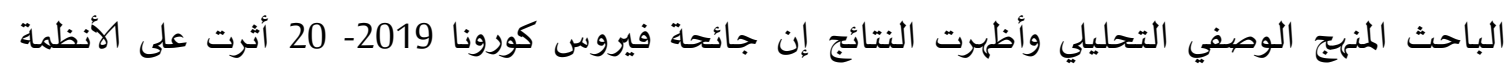

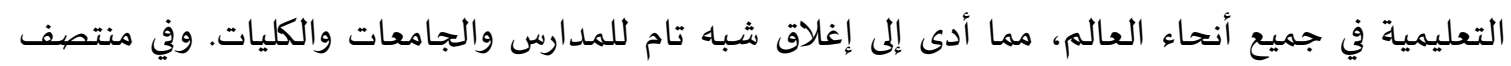

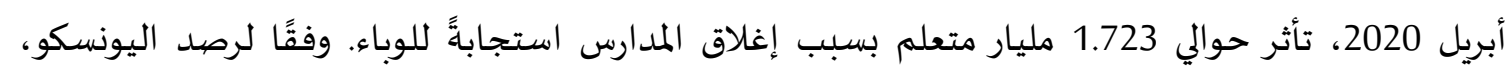

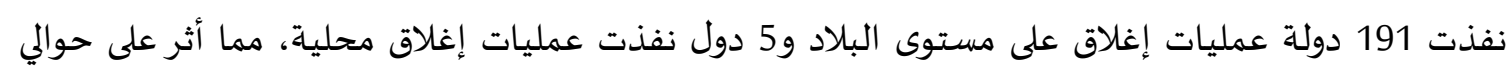

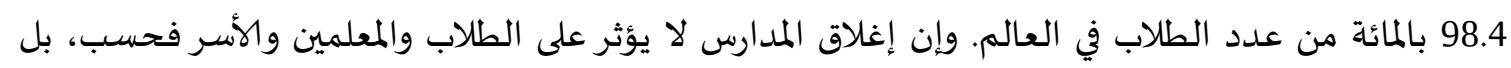

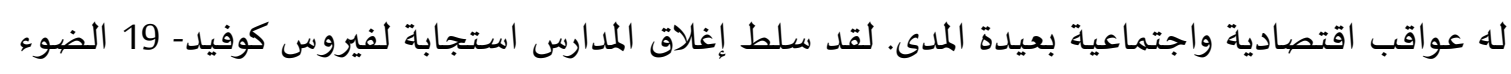

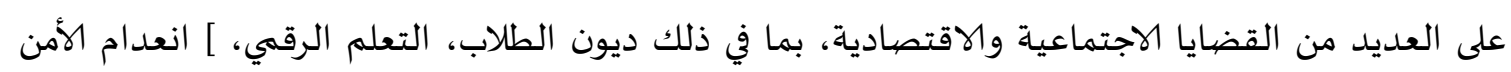

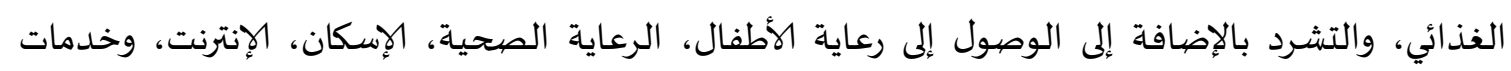

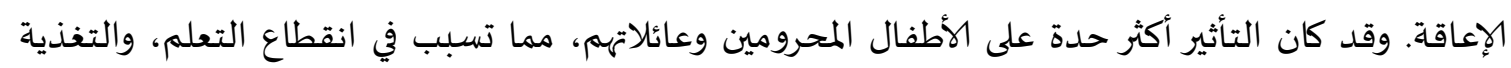

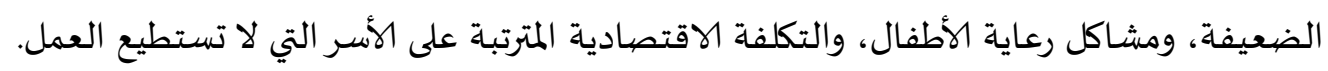

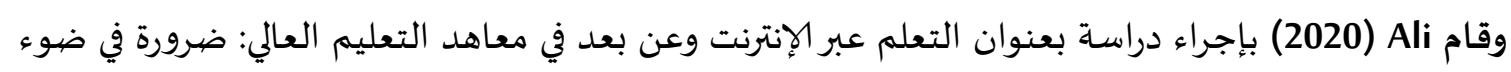

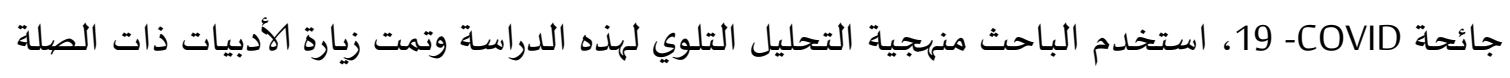

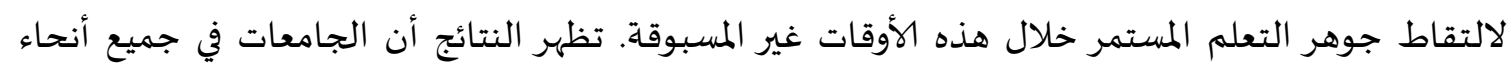

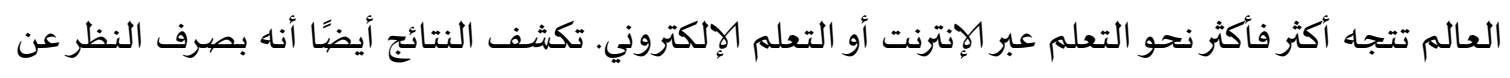
الموارد، فإن استعداد الموظفين والثقة وإمكانية وصيول الطلاب وتحفيزهم تلعب وظيفة مهمة في التعلم المتكامل

لتكنولوجيا المعلومات والاتصالات.

3- منهجية الدراسة وإجراءاتها.

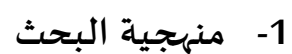

استخدم الباحثان المنهج الوصفي المستي التحليلي القائم على التحليل والتفسير الدقيق للنصوص

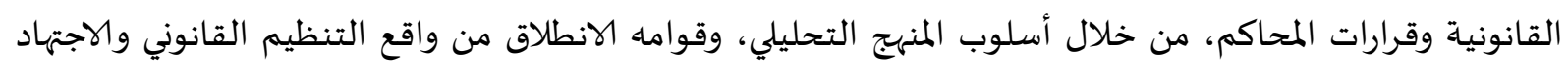

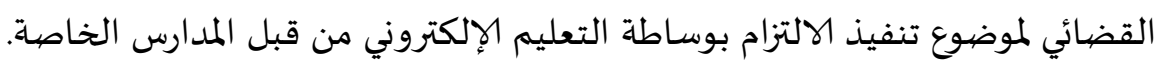

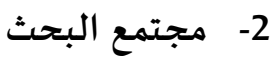
تكون مجتمع البحث من أولياء الامور في منطقة شفابدران- حي الكوم والبالغ عددهم تقريبا 250 ولي أمر. 
تكونت عينة البحث بصورتها النهائية من 34 ولي أمر، وكان يطمح الباحثان للحصول على عينة كبيرة، حيث

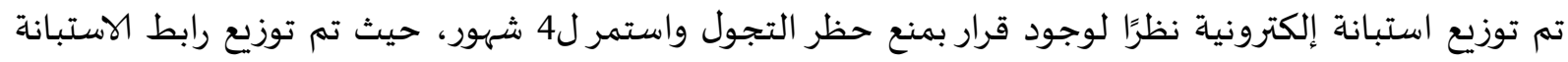

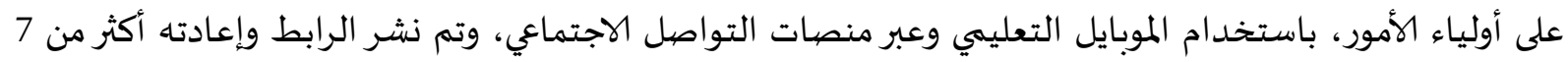

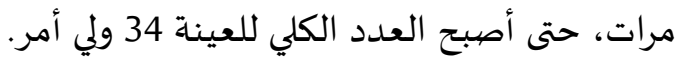

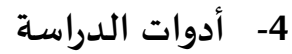

استخدم الباحثان أدوات تحليل الوثائق والاستبانة الإلكتروني، بعد التأكد من صدقها وثباتها.

5- صهدق أداة الاستبانة الإكترونية

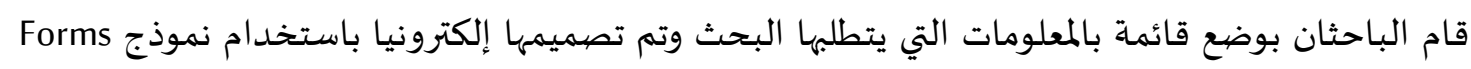

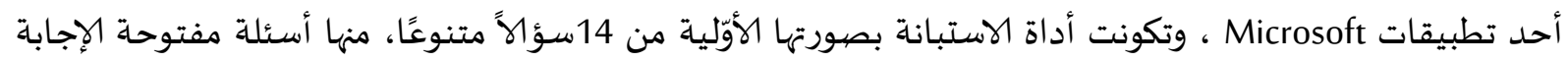
ومقيدة الإجابة، وبحسب سلم ليكرت بعضها خماسي (موافق بشدة، موافق، محايد، غير موافق، غير موافق بشدة)

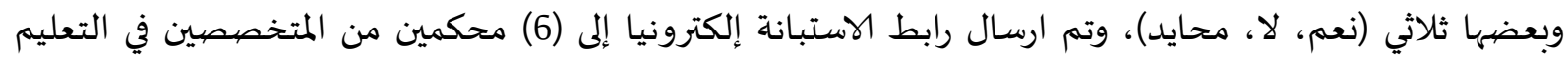

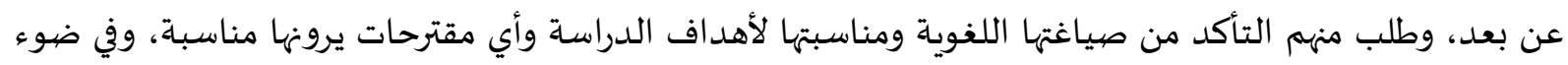
ذلك تم تعديل الاستبانة واستقرت على 15 سؤالًً متنوعًا.

6- - مبات الأداة

تم إيجاد معامل الثبات كرونباخ الفا، وقد بلغ (0.79) ويعتبر معامل مقبول بحثيا.

7- المعالجة الإحصائية

استخدم الباحثان التكرارات والنسب المئوية، للإجابة عن الأسئلة المتعلقة بالبعد التربوي.

4- - عرض النتائج ومناقشتها

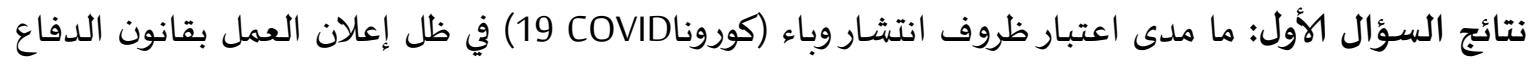

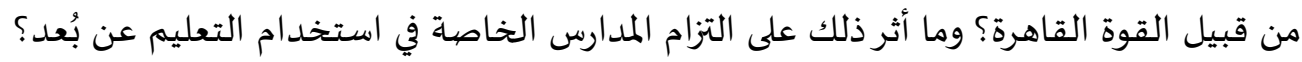

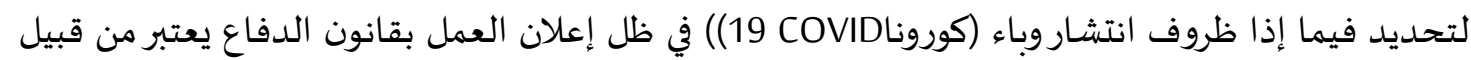

القوة القاهرة، يتوجب النظر إلى كل واقعة على حدة. وما يهمنا في هذه الورقة البحثية هو المدارس الخاصية،

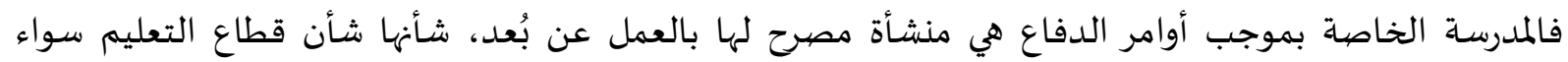

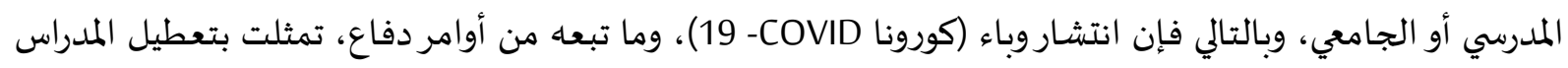

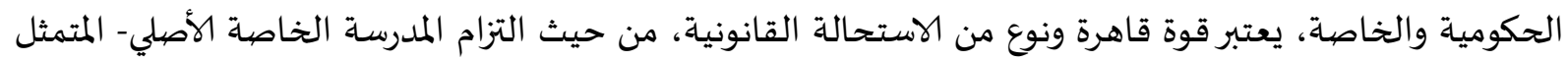

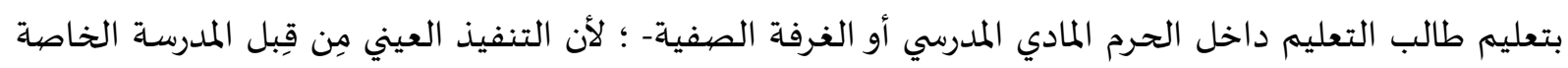

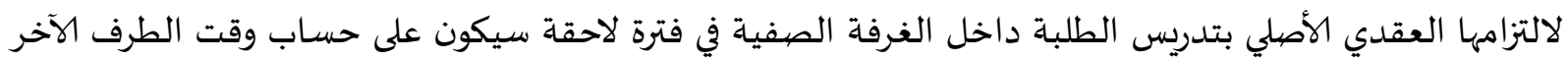

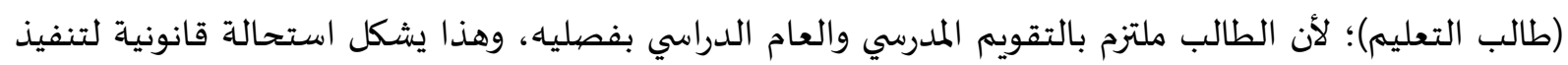


إلا أنه وعلى ضوء التصريح بموجب أمر الدفاع للمدرسة الخاصة بالعمل عن بُعد (قرار مجلس الوزراء رقم

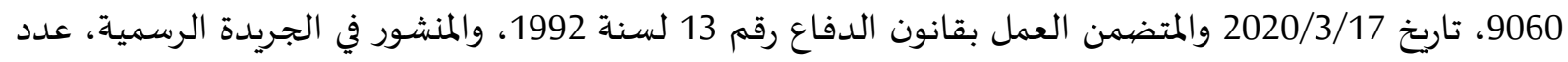

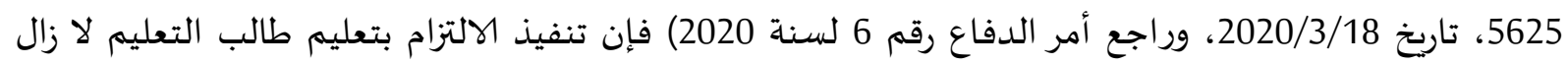

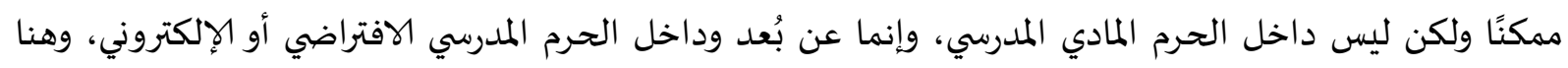

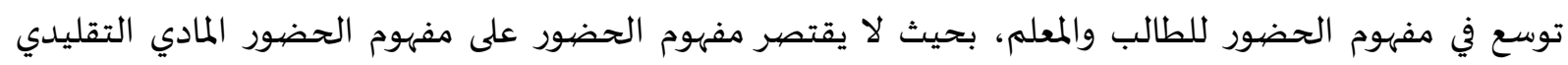

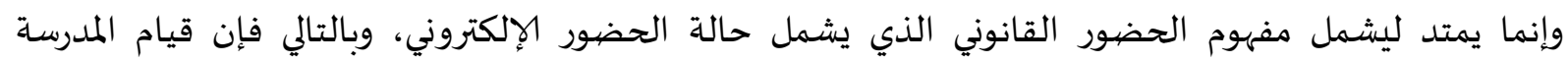

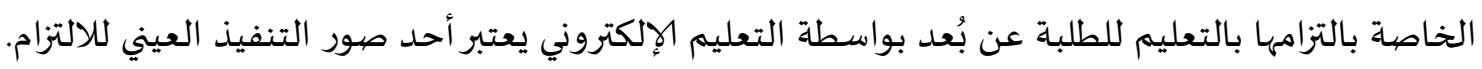

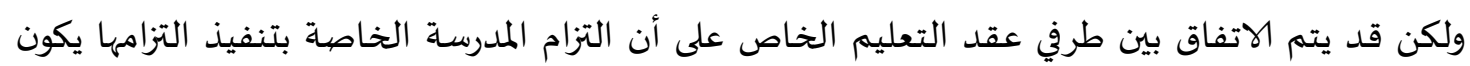

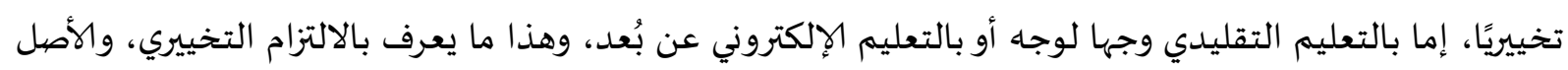

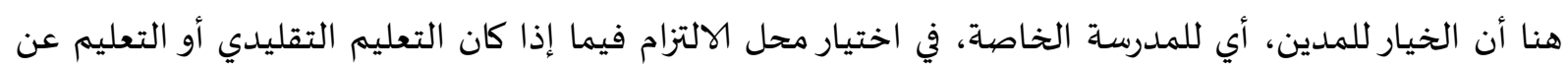

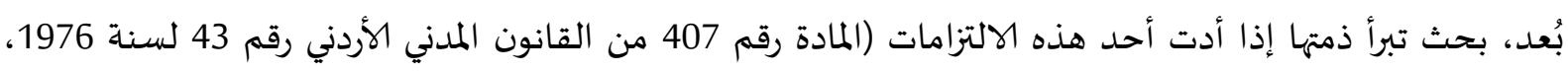

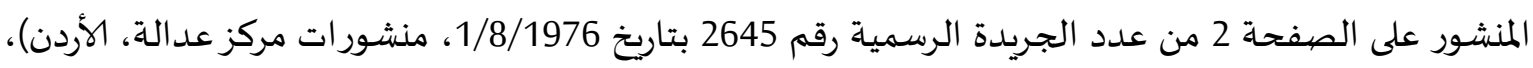

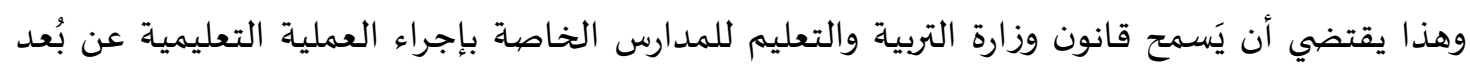

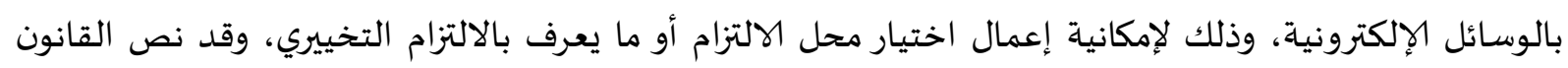

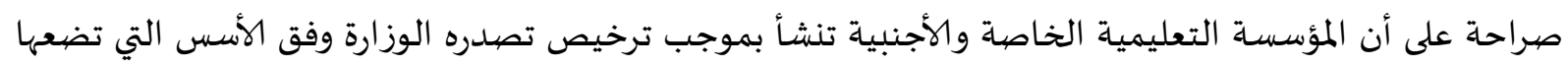

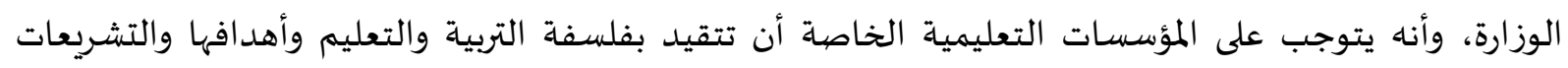

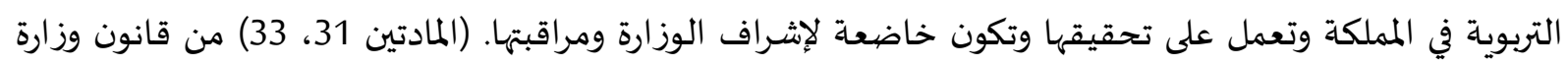

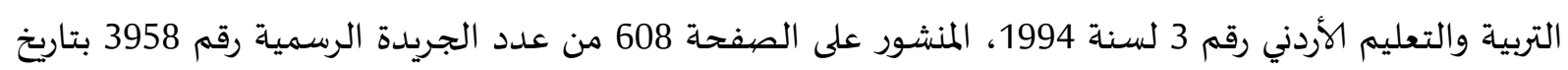

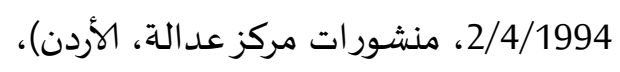

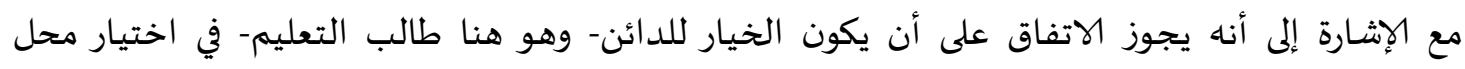

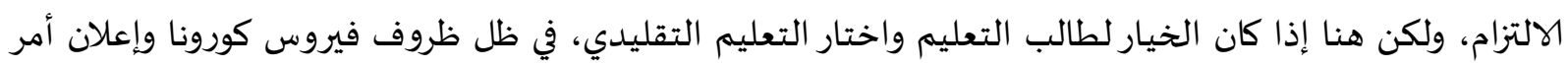

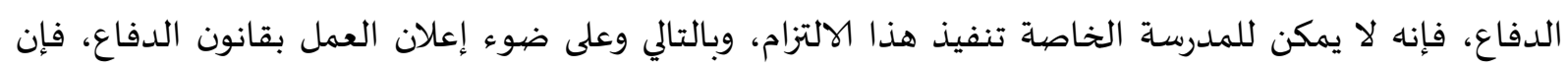

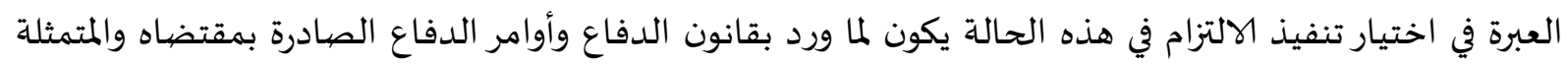

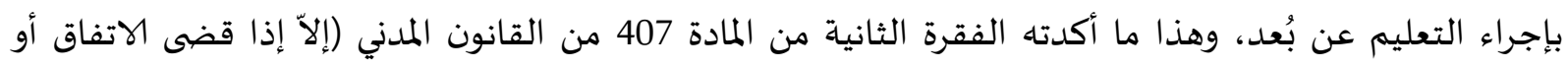

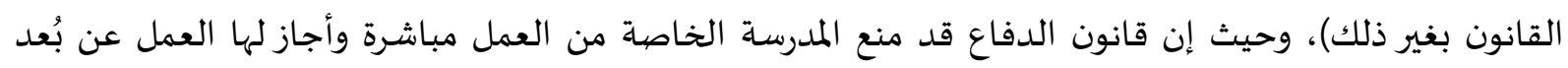

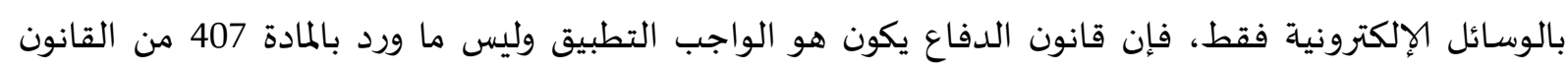

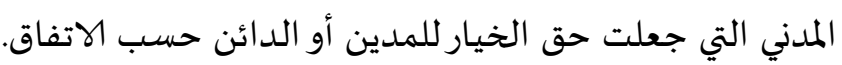

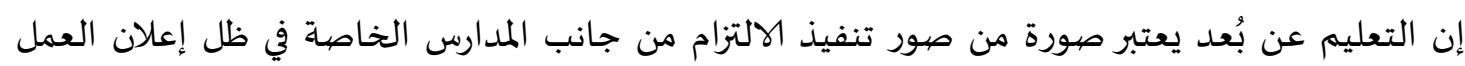

بقانون الدفاع بسبب فيروس كورونا والسماح للمدرسة الخاصة بالعمل عن بُعد بوساطة الوسائل الإلكترونية.

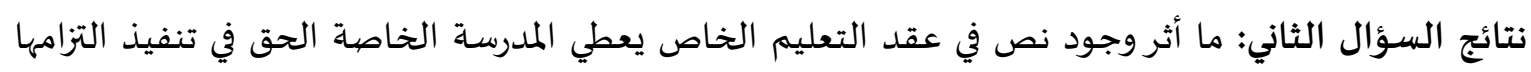

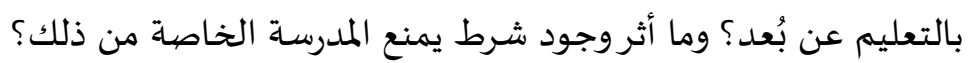

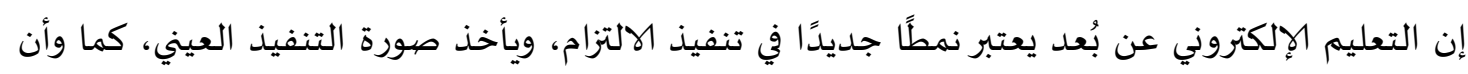

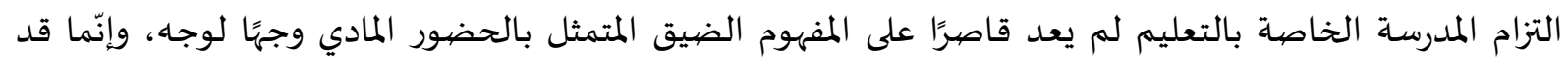

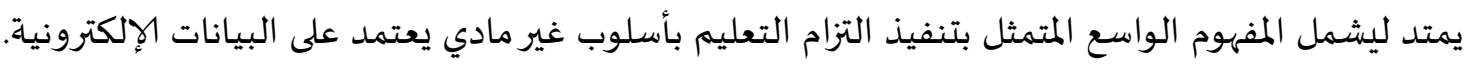


نتائج السؤال الثالث: هل أساليب التعليم عن بُعد- المستخدَمة من المدارس الخاصية- راعت الفروق الفردية

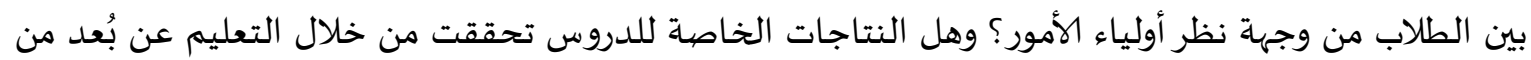
وجهة نظر أولياء الأمور؟ من اجنه أظهرت النتائج أن (65\%) من أولياء الأمور أكدوا أن أساليب التعليم عن بُعد- المستخدمة من المدارس ألماء

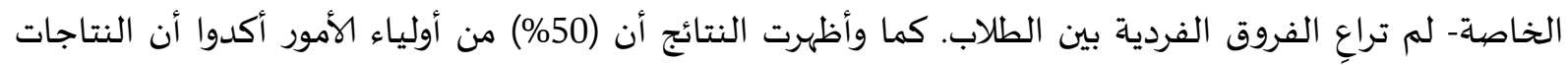
الخاصة للدروس لم تتحقق من خلال التعليم عن بُعد.

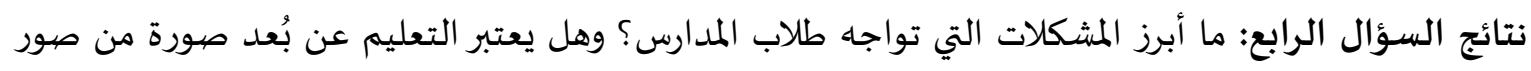

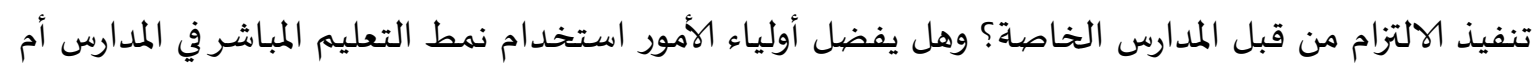

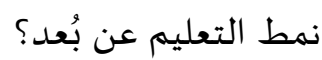
أظهرت النتائج أن (70\%) من أولياء الأمور أكدوا أن أبرز المشكلات التي تواجه أبناءهم من خلال التعليم

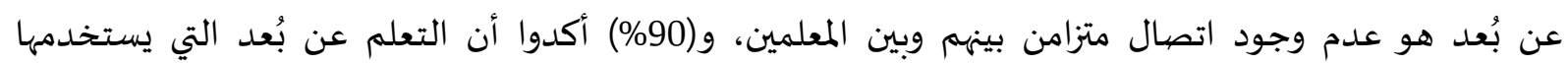

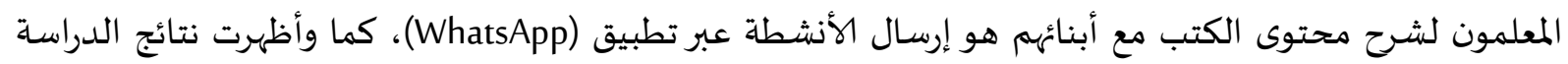

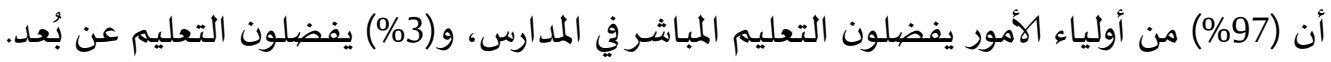

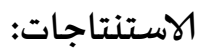

إن اعتبار التعليم عن بُعد، مِن قِبل المدارس الخاصية، وسيلة من وسائل تنفيذ الالتزام يعتمد على كل حالة

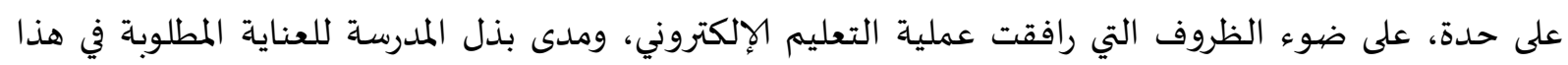

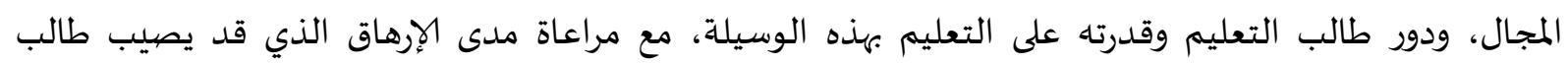

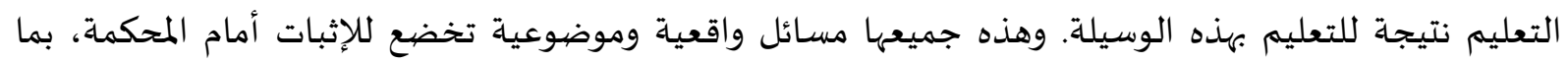

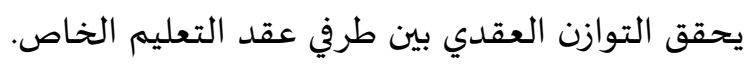

$$
\text { التوصيات والمقترحات. }
$$

$$
\text { استنادا لنتائج الدراسة يوصي الباحثان ويقترحان الآتي: }
$$

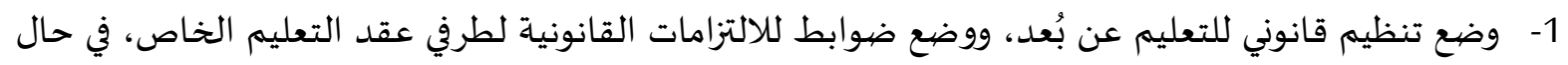

تنفيذ الالتزام بالوسائل الإلكترونية.

2- زيادة الرقابة على المدارس الخاصة من قبل وزارة التربية والتعليم، للاهتمام بأمور التعليم عن بعد.

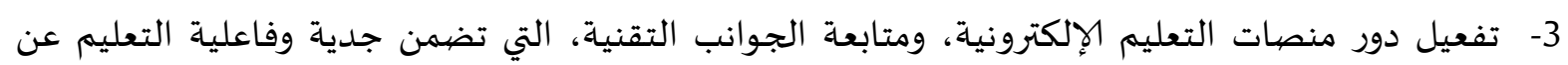

4- تعديل قانون وزارة التربية والتعليم، والتوسع في مفهوم التعليم، ليشمل التعليم التقليدي والتعليم عن بعد. 5- إجراء دراسات مماثلة حول موضوع الدراسـة.

قائمة المراجع

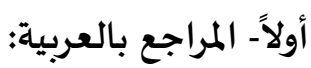

https: تقرير منظمة الامم المتحدة للتربية والثقافة اليونسكو، (2020)، استرجع من الموقع الإلكتروني للمكتبه .//ar.unesco.org/fieldoffice/beirut 
تقرير منظمة اليونيسيف، (2020)، استرجع من الموقع الإلكتروني /https://www.unicef.org.

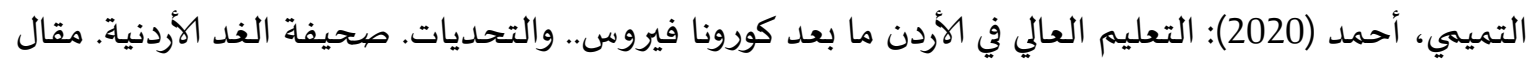

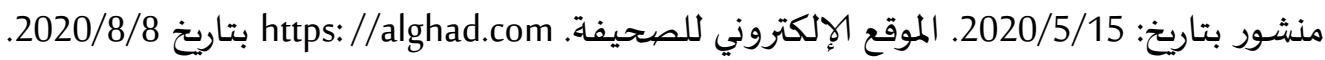

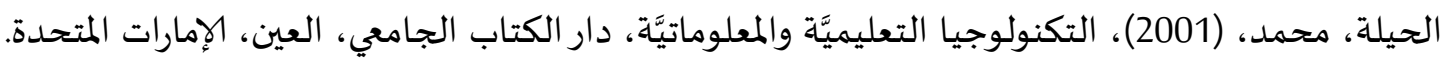

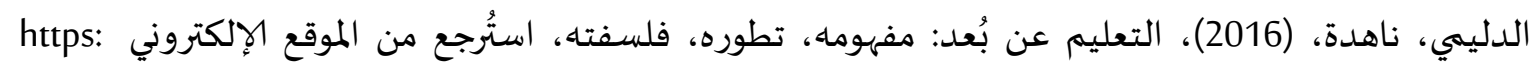
.//www.edutrapedia.com السرحان، عدنان، خاطر ونوري، (2000)، مصادر الحقوق الشخصية "الالتزامات"، ط1، دار الثقافة للنشر والتوزيع، عمان، الأردن. سلطان، أنور، (2007)، مصادر الالتزام في القانون المدني الأردني، ط1، دار الثقافة للنشر والتوزيع، عمان، الأردن السنهوري، عبد الرازق، (2010)، الوسيط في شرح القانون المدني الجديد، ط3، الجزء الثالث، منشورات الحلبي الحقوقية، بيروت، لبنان. سوهام، بادي، (2009)، سياسات واستراتيجيات توظيف تكنولوجيا المعلومات في التعليم، رسالة ماجستير غير لينان منشورة، جامعة منتوري، الجزائر.

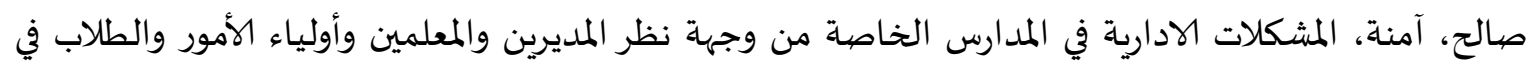
محافظات شمال فلسطين، رسالة ماجستير، 2004، جامعة النجاح الوطنية.

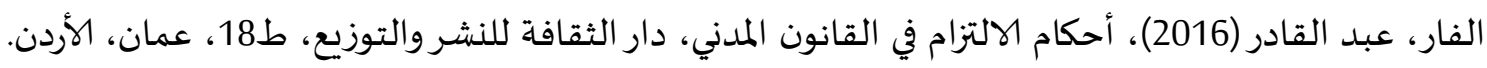

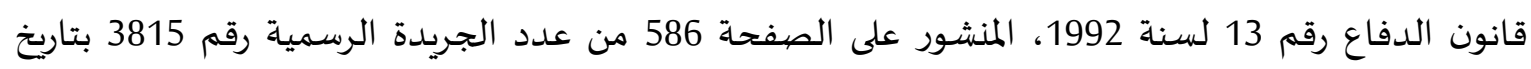
1992/3/25، منشورات مركز عدالة، الأردن. القانون المدني الأردني رقم 43 لسنة 1976، المنشور على الصفحة 2 من عندان عدد الجريدة الرسمية رقم 2645 بتاريخ 1976/8/1

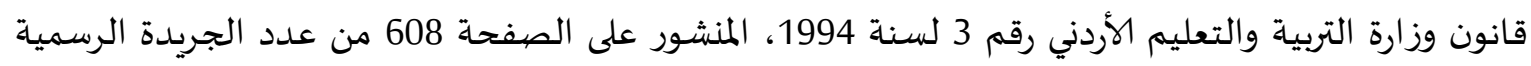

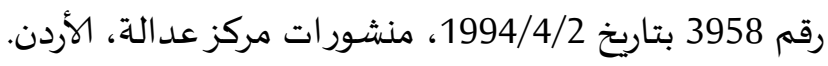

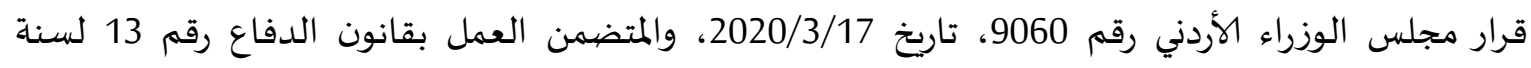

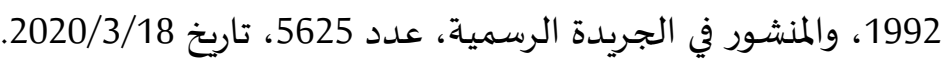

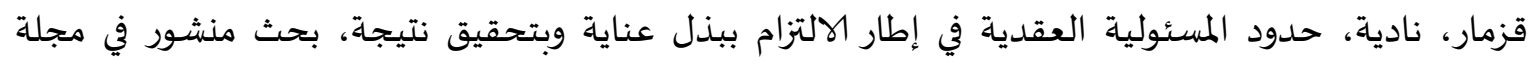
بحوث الشرق الأوسط، العدد 48.

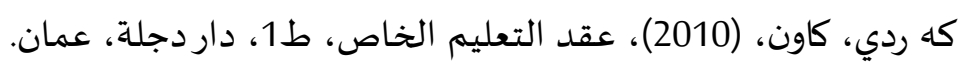

\section{ثانياً- المراجع بالإنجليزية:}

- Ali,W. (2020), Online and Remote Learning in Higher Education Institutes: A Necessity in light of COVID- 19 Pandemic. Higher Education Studies, 10(3),16- 25.

- Basilaia, G., et al. (2020) 'Replacing the Classic Learning Form at Universities as an Immediate Response to the COVID- 19 Virus Infection in Georgia', International Journal for Research in Applied Science \& Engineering Technology (IJRASET), 8(III), 101- 108. 
- Basilaia,G. Dgebuadze, M. Kantaria, M. and Chokhonelidze, G, (2020), Replacing the Classic Learning Form at Universities as an Immediate Response to the COVID- 19 Virus Infection in Georgia. International Journal for Research in Applied Science \& Engineering Technology (IJRASET), 8(111),101- 110.

- Basilia, G. and kvavadze,D. (2020), Transition to Online Education in Schools during a SARS- CoV- 2 Coronavirus (COVID- 19) Pandemic in Georgia. Pedagogical Research, 5(4),1- 9.

- Mustafa, N. (2020), Impact of the 2019-20 coronavirus pandemic on education. International Journal of Health Preferences Research,1(1),1-12.

- Onyema, E. Eucheria, N. Ayobamidele, F. Sen,S. Atonye,F. Sharma.A. and Alsayed, A. (2020), Impact of Coronavirus Pandemic on Education. Journal of Education and Practice,11(13), 108- 120.

- Sintema, E. (2020), Effect of COVID- 19 on the Performance of Grade 12 Students: Implications for STEM Education. EURASIA Journal of Mathematics, Science and Technology Education,16(7),1- 6. 